\title{
strastant

\section{Wheel Wear Related Instability in Grinding of Quartz Glass}

\section{Yonghao Wang}

Dalian University of Technology

Ping Zhou ( $\nabla$ pzhou@dlut.edu.cn )

Dalian University of Technology

\section{Yuhang Pan}

Dalian University of Technology

\section{Ying Yan}

Dalian University of Technology

\section{Dongming Guo}

Dalian University of Technology

\section{Research Article}

Keywords: Grinding stability, Wheel wear, Grinding force, Surface roughness

Posted Date: May 7th, 2021

DOl: https://doi.org/10.21203/rs.3.rs-424350/v1

License: (c) (1) This work is licensed under a Creative Commons Attribution 4.0 International License. Read Full License

Version of Record: A version of this preprint was published at The International Journal of Advanced Manufacturing Technology on October 28th, 2021. See the published version at https://doi.org/10.1007/s00170-021-08189-7. 


\title{
Wheel wear related instability in grinding of quartz glass
}

\author{
Yonghao Wang ${ }^{1}$, Ping Zhou ${ }^{1 *}$, Yuhang Pan $^{1}$, Ying Yan $^{1}$, Dongming Guo ${ }^{1}$ \\ ${ }^{1}$ Key Laboratory for Precision and Non-traditional Machining Technology of Ministry of Education, Dalian \\ University of Technology, Dalian 116024, China
}

\begin{abstract}
Grinding is a popular method for producing high-quality parts made of hard and brittle materials. A lot of researchers have focused on the impact of grinding parameters on surface quality. However, only a few studies discussed the surface quality instability caused by the grinding wheel wear during a long grinding process. In this paper, through wheel state monitoring and surface quality testing of ground samples, it is found that the relationship between ground surface roughness and theoretical undeformed chip thickness is significantly affected by the grinding wheel wear state, rather than maintain steady as described in most available models. By introducing the normal grinding force, a linearly relationship was found among normal grinding force, undeformed chip thickness and ground surface roughness. Besides, sensitivity analysis was conducted to guide the parameter adjustment to maintain the stability of ground surface roughness and grinding state. The mechanism of the effect of wheel wear on normal grinding force was also studied in detail. This study will help to further understand the mechanism of the

\footnotetext{
* Corresponding author.
}

E-mail address: pzhou@dlut.edu.cn (P. Zhou).
\end{abstract}


influence of wheel wear on the grinding stability.

Keywords: Grinding stability; Wheel wear; Grinding force; Surface roughness
Abbreviations
$a_{\mathrm{p}} \quad$ Depth of cut in $\mu \mathrm{m}$
$A_{\mathrm{p}} \quad$ Depth of cut in $\mathrm{m}$
C Number of cutting points per area
$d_{\mathrm{e}} \quad$ Equivalent diameter of grinding wheel
D Diameter of the grinding wheel
$E\left(R_{\mathrm{a}}\right) \quad$ Expected value of surface roughness $R_{\mathrm{a}}$
$E(t) \quad$ Expected value of undeformed chip thickness
$f \quad$ Overlap factor
$F_{\mathrm{n}} \quad$ Normal grinding force
$h_{\mathrm{w}} \quad$ Reduction of abrasive grits protrusion height caused by grinding wheel wear
$k \quad$ Synthesized parameter of $V_{\mathrm{s}}, V_{\mathrm{w}}$ and $A_{\mathrm{p}}$
$M R V_{41 \mathrm{Cr} 4} \quad$ Material removal volume of $41 \mathrm{Cr} 4$ in the preparation of wear grinding wheel
$N_{\mathrm{d}} \quad$ Number of dynamic active grits
$P_{0} \quad$ Constant determined by experiment
$r \quad$ Aspect ratio of the chip section
$R_{\mathrm{a}} \quad$ Arithmetical mean roughness of grinding surface 


$\begin{array}{ll}S_{\mathrm{w}} & \text { Tip area of the worn grit } \\ t_{\mathrm{m}} & \text { Maximum undeformed chip thickness } \\ v_{\mathrm{s}} & \text { Grinding wheel speed in } \mathrm{rpm} \\ v_{\mathrm{w}} & \text { Workpiece infeed rate in } \mathrm{mm} / \mathrm{min} \\ V_{\mathrm{s}} & \text { Feed speed in } \mathrm{m} / \mathrm{s} \\ V_{\mathrm{w}} & \quad \text { Peripheral speed of grinding wheel in } \mathrm{m} / \mathrm{s} \\ \delta_{n, n+1} & \quad \text { Change in normal grinding force between wear stage } n \text { and wear stage } n+1\end{array}$

\section{Introduction}

Grinding is considered as a high-efficiency and low-cost finishing operation [1]. It is a major manufacturing process that accounts for about $20-25 \%$ of the total expenditures on machining operations in industrialized countries [2]. It is also a vital technology for producing parts made of hard and brittle materials. Grinding is a complicated process viewed as the combination of several micro-machining processes performed by individual abrasive grits in the wheel [3]. The performance of ground parts is sensitive to the surface quality determined by the action of abrasive grits. During the grinding process, abrasive grits are wearing all the time, which results in the variation of the contact state between grinding wheel and workpiece. This variation leads to the instability of product quality.

To improve the stability of the ground surface quality, it is necessary to reveal the factors that dominate the surface quality. Surface roughness is a widely used and convenient parameter to characterize the ground surface quality [4], [5]. Many researchers focused on the effect of 
grinding processing parameters including the grinding wheel speed, workpiece feed rate, and depth of cut on the ground surface roughness. Malkin et al. [2] considered three grinding parameters and proposed a theoretical model to calculate the maximum undeformed chip thickness. Their model became the basis for many subsequent research works on grinding roughness prediction models. There are a lot of experimental studies to analyze the influence of processing parameters on the ground surface roughness [6]-[9], and these processing parameters are also the most widely used input parameters in regression [10], [11] and artificial intelligence analysis [12], [13] based on experimental data. Except for the processing parameters, some other parameters have been found to significantly affect the ground surface roughness. Agarwal et al. [14], [15] proposed a model to predict grinding surface roughness which considered the crosssection of scratch as a semicircle. In contrast, Sun et al. [16] considered the cross-section of abrasive grits as a parabola and modified the former model to obtain a new roughness prediction model. Liu et al. [17] presented a comprehensive study of a computationally efficient kinematic simulation to predict workpiece surface roughness in grinding using three different abrasive grit shapes (sphere, truncated cone, and cone). These researches showed that the cross-sectional shape of abrasive grits has a non-negligible effect on surface roughness. Besides, there are some other parameters, such as abrasive radius [18] and the height of the cutting edge [19], also influence the ground surface roughness. These abrasive grits related parameters are sensitive to wheel wear and are unsteady during the grinding process. With the wear of abrasive grits, it is conceivable that the quality of the ground surface is continuously changing. However, few models can consider the influence of abrasive grit morphology caused by wheel wear. Moreover, 
the wear state of the abrasive grits is difficult to be monitored in real-time. To realize the stability of the grinding process and intelligent adjustment of processing parameters, it is important to find an intermediate parameter that reflects the effect of abrasive grit wear on the ground surface quality.

The continuous wear of the grinding wheel has a great impact on the machining results. There are several indirect approaches to detect the grinding wheel wear, such as optical methods [20], [21], wear reprography [22], acoustic emission(AE) signal [23]-[27] and grinding force signal. Among the above methods, grinding force monitoring is a convenient method to detect the wear of grinding wheel. A lot of research results have shown that the wear of the grinding wheel has an influence on grinding force, so grinding force can be used for the detection and evaluation of the wear state of grinding wheel. Previous studies showed that an increase of grinding force signal is related to the wheel dulling [28]. Nguyen et al. [29] used the grinding force signal to monitor the grinding wheel wear. The mean value and root mean square (RMS) value of normal grinding force were extracted from the force signal. When the grinding wheel was dull, the mean value and RMS value of the force signal increased accordingly. Except for grinding force mean value and RMS value, more characteristic parameters of the grinding force were studied by Kannan et al. [30]. They extracted the AR- 8 coefficient, the mean wavelet level 1 approximate coefficient, the correlation dimension from the grinding force signal. These characteristic parameters showed similar trends with the progress of wheel wear and it was found that these parameters will increase with the wheel wear exacerbates. Zhang et al. [31] simulated the grinding process of abrasive grits, and the results showed that the grinding force was 
positively correlated with the contact area between abrasive grits and workpiece. This research was helpful to understand why the grinding force increases with grinding wheel wear progresses. These research results have shown that it is feasible to use the grinding force to characterize the grinding wheel wear.

Additionally, it is necessary to know whether the change in grinding force due to wheel wear has a significant effect on the ground surface roughness. Sevaraj et al. [32] studied the changes in cutting force and surface roughness with wheel wear. Their results showed that cutting force and surface roughness have similar trends with the wheel wear exacerbating. Zhu et al. [33] found a certain relationship between grinding force and machined surface roughness. Therefore, the normal grinding force could be used as the characteristic parameter of grinding wheel wear to learn the further relationship between wheel wear and ground surface roughness. However, how to use the grinding force to judge the wear state of the grinding wheel and predict the roughness more accurately remains to be studied.

With the development of artificial intelligence, intelligent manufacture will be an important form of processing in the future. To achieve the purpose, the grinding situation should be monitored online and the wheel wear is then an important factor that affects the grinding quality. When the grinding wheel is worn and the shape of abrasive grits changes, the prediction results of the models that considering only processing parameters will have a large deviation. To fill this gap, the changes caused by grinding wheel wear is monitored through the normal grinding force. Through the introduction of the normal grinding force, the wear factor is incorporated into the roughness prediction model to achieve a more accurate prediction result. Besides, the sensitivity 
of ground surface roughness and normal grinding force to machining parameters and grinding wheel wear is also analyzed in this paper. And the results can be used to guide the adjustment of grinding parameters and ensure the stability of the grinding process.

\section{Methodology}

\subsection{Experimental materials}

The material of specimens used in this experiment was quartz glass. The quartz glass had a hardness of 5.5 HM, bending strength of $67 \mathrm{MPa}$, and elasticity modulus of $72 \mathrm{GPa}$, as presented in Table 1. The specimens had dimensions of $15 \mathrm{~mm} \times 15 \mathrm{~mm} \times 10 \mathrm{~mm}$.

\subsection{Experiment setup and conditions}

The grinding experiment was conducted on a computer numerical control (CNC) milling machine NHM 800, $10 \mathrm{~kW}$. Firstly, the specimens were glued on an iron block. Secondly, the iron block was clamped with a flat-nose plier. Thirdly, the flat-nose plier was fixed on the dynamometer, shown in Fig. 1.

Table 1 The properties of the quartz workpiece used in the experiment

\begin{tabular}{ccccc}
\hline Density & Hardness & Bending strength & Fracture toughness & Elasticity modulus \\
\hline $2.2 \mathrm{~g} / \mathrm{cm}^{3}$ & $5.5 \mathrm{HM}$ & $67 \mathrm{MPa}$ & $15.9 \mathrm{GPa}$ & $72 \mathrm{GPa}$ \\
\hline
\end{tabular}



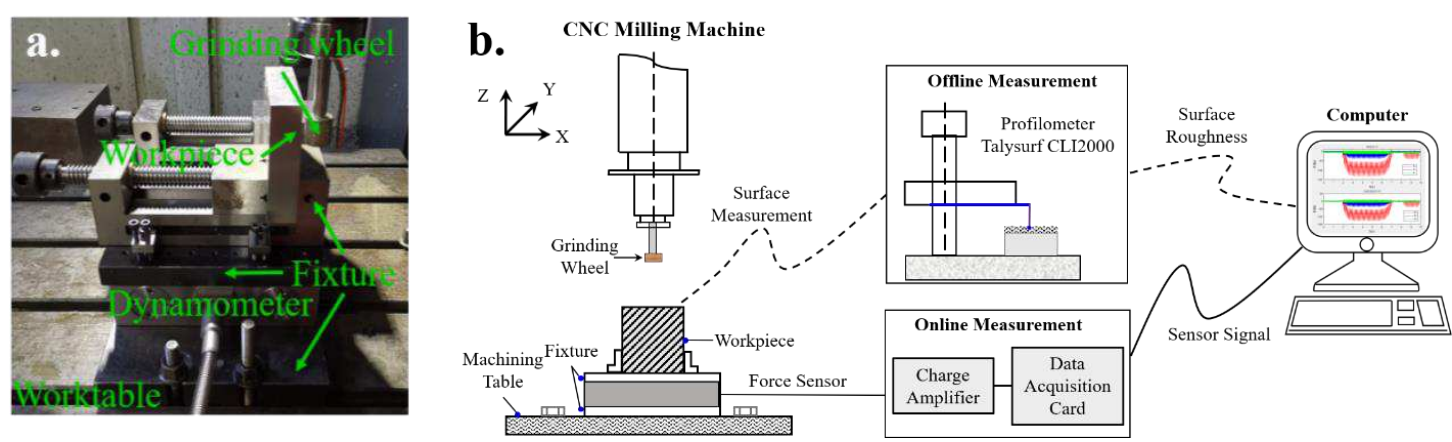

Fig. 1 Schematic diagram of the grinding experiment setup

An electroplated diamond grinding wheel with 80 grit was used in this experiment. The grit size was about $190 \mu \mathrm{m}$. The diameter and width of the grinding wheel were $20 \mathrm{~mm}$ and $20 \mathrm{~mm}$ respectively. The grinding process was conducted without coolant. The levels of three grinding parameters are listed in Table 2.

Table 2 Process control parameters and their range

\begin{tabular}{ccccccc}
\hline & & & \multicolumn{3}{c}{ Levels } \\
\cline { 4 - 6 } Factors & Parameters & Units & Notation & \multicolumn{3}{c}{3} \\
\hline A & Wheel speed & $\mathrm{rpm}$ & $v_{\mathrm{s}}$ & 500 & 2000 & 5000 \\
$\mathrm{~B}$ & Workpiece feed & $\mathrm{mm} / \mathrm{min}$ & $v_{\mathrm{w}}$ & 100 & 200 & 500 \\
$\mathrm{C}$ & Grinding depth & $\mu \mathrm{m}$ & $a_{\mathrm{p}}$ & 50 & 100 & 150 \\
\hline
\end{tabular}

In the long grinding process, grinding wheel wear will affect the stability of the grinding quality. However, the wear of grinding wheel is not obvious in a short time grinding of quartz. 
Therefore, before the quartz grinding test, the grinding wheel was used to grind a $41 \mathrm{Cr} 4$ steel sample to accelerate the wheel wear. When the material removal volume of $41 \mathrm{Cr} 4$ steel $\left(M R V_{41 \mathrm{Cr} 4}\right)$ was $735,3045,13545,29295$, and $50295 \mathrm{~mm}^{3}$, the grinding wheel was marked as stage 1 , stage 2 , stage 3 , stage 4 , and stage 5 respectively. In different wear stages, grinding experiments of quartz samples were carried out and two workpieces were ground without coolant for each set of processing parameters.

\subsection{Measurement method}

In different wear stages, the grinding wheel topography was measured in a laser scanning confocal microscope (KEYENCE VK-X260K). Five busbars were evenly chosen on the cylindrical surface of the grinding wheel, and three positions on each busbar were taken for the wheel topography measurement. After the wheel topography measurement, the grinding experiment of quartz glass was performed.

During the grinding process, the grinding force was measured using a piezoelectric dynamometer Kistler 9139 AA2, and the sampling frequency was set to $10 \mathrm{kHz}$ to collect the grinding force signal. Then the force signal was subjected to Butterworth low-pass filtering with a cut-off frequency of $2 \mathrm{~Hz}$, and the mean and standard deviation value of the force signal was calculated from the filtered force signal.

After grinding, the surface roughness of the workpiece was measured by a profilometer (Talysurf CLI2000). Every workpiece was tested in 5 different positions. The sampling length was randomly select to pre-measure the roughness of the ground surface. Results showed that the roughness was in the range of 3 to 9 microns. According to this result, the final sampling 
length was selected as $2.5 \mathrm{~mm}$ and the data length was selected as $8 \mathrm{~mm}$. The topography of the ground surface was measured by a laser scanning confocal microscope (KEYENCE VK-X260K) and a scanning electron microscope (FEI QUANTA 450).

\section{Results and discussions}

\subsection{The influences of wheel wear on grinding force and surface roughness}

During the grinding process, the abrasive grits were continuously worn, showing as attrition wear, fracture, and grits dropped-out. At the same cutting depth, the greater the wear, the larger the contact area between abrasive grits and workpiece will be, thus the grinding force increases with abrasive grits wear [31].

The experiment data were shown in Table 3. The topography of the grinding wheel and ground surface in different wear stages were shown in Fig. 2 and Fig.3. In stage 2, the attrition wear of abrasive grits was observed. In this stage, most of the abrasive grits have sharp edges, and the normal grinding force was $35.11 \mathrm{~N}$ in trail No. 2. Obvious groove marks and significant material fragmentation were also observed on the ground surface in stage 2 (Fig. 3). As the wear intensified, the attrition wear of abrasive grits gradually exacerbated, which was manifested as the increase of the wear area. Besides, the abrasive grits fracture and dropped-out (Fig. 2) occurred. These phenomena caused the abrasive cutting edge to become blunt, which in turn led to an increase in the grinding force and the material was broken into finer pieces (Fig. 3). As the wear of the grinding wheel increased, the grinding force further increased, while the grinding surface tended to be flat and the fragment became finer. 
Table 3 The experiment parameters and results

\begin{tabular}{|c|c|c|c|c|c|c|c|c|c|c|c|c|c|}
\hline \multirow{2}{*}{ No. } & \multirow{2}{*}{$\begin{array}{c}v_{\mathrm{s}} \\
(\mathrm{rpm})\end{array}$} & \multirow{2}{*}{$\begin{array}{c}v_{\mathrm{w}} \\
(\mathrm{mm} /\end{array}$} & \multirow{2}{*}{$\begin{array}{c}a_{\mathrm{p}} \\
(\mu \mathrm{m})\end{array}$} & \multicolumn{2}{|c|}{ Stage 1} & \multicolumn{2}{|c|}{ Stage 2} & \multicolumn{2}{|c|}{ Stage 3} & \multicolumn{2}{|c|}{ Stage 4} & \multicolumn{2}{|c|}{ Stage 5} \\
\hline & & & & $R_{\mathrm{a} 1}$ & $F_{\mathrm{n} 1}$ & $R_{\mathrm{a} 2}$ & $F_{\mathrm{n} 2}$ & $R_{\mathrm{a} 3}$ & $F_{\mathrm{n} 3}$ & $R_{\mathrm{a} 4}$ & $F_{\mathrm{n} 4}$ & $R_{\mathrm{a} 5}$ & $F_{\mathrm{n} 5}$ \\
\hline 1 & 500 & 100 & 50 & 6.90 & 10.82 & 4.92 & 14.52 & 3.49 & 51.44 & 3.92 & 61.32 & 3.46 & 107.30 \\
\hline 2 & 500 & 200 & 100 & 7.26 & 24.81 & 6.49 & 35.11 & 4.45 & 91.07 & 4.65 & 125.32 & 3.69 & 212.40 \\
\hline 3 & 500 & 500 & 150 & 7.62 & 73.28 & 7.27 & 88.46 & 5.11 & 167.67 & 5.34 & 213.42 & 4.43 & 299.77 \\
\hline 4 & 2000 & 100 & 100 & 7.76 & 3.98 & 5.87 & 6.99 & 3.36 & 39.31 & 4.13 & 81.05 & 3.26 & 104.92 \\
\hline 5 & 2000 & 200 & 150 & 7.65 & 13.01 & 6.84 & 17.74 & 3.32 & 70.08 & 4.07 & 122.97 & 3.78 & 150.88 \\
\hline 6 & 2000 & 500 & 50 & 7.31 & 10.16 & 6.96 & 12.40 & 3.73 & 43.39 & 4.22 & 77.69 & 3.50 & 97.19 \\
\hline 7 & 5000 & 100 & 150 & 7.16 & 3.37 & 6.04 & 5.91 & 3.75 & 23.53 & 3.59 & 35.26 & 3.78 & 36.54 \\
\hline 8 & 5000 & 200 & 50 & 7.71 & 2.74 & 5.53 & 3.98 & 3.57 & 12.04 & 3.71 & 21.73 & 3.65 & 22.15 \\
\hline 9 & 5000 & 500 & 100 & 8.30 & 8.59 & 6.03 & 12.83 & 3.99 & 41.76 & 3.62 & 98.72 & 3.99 & 89.96 \\
\hline
\end{tabular}

The value of $R_{\mathrm{a}}$ and $F_{\mathrm{n}}$ is the average value of two grinding tests

According to the maximum undeformed chip thickness equation [2]:

$$
t_{\mathrm{m}}=\left[\frac{6}{C r}\left(\frac{V_{\mathrm{w}}}{V_{\mathrm{s}}}\right)\left(\frac{A_{\mathrm{p}}}{d_{\mathrm{e}}}\right)^{\frac{1}{2}}\right]^{\frac{1}{2}}
$$




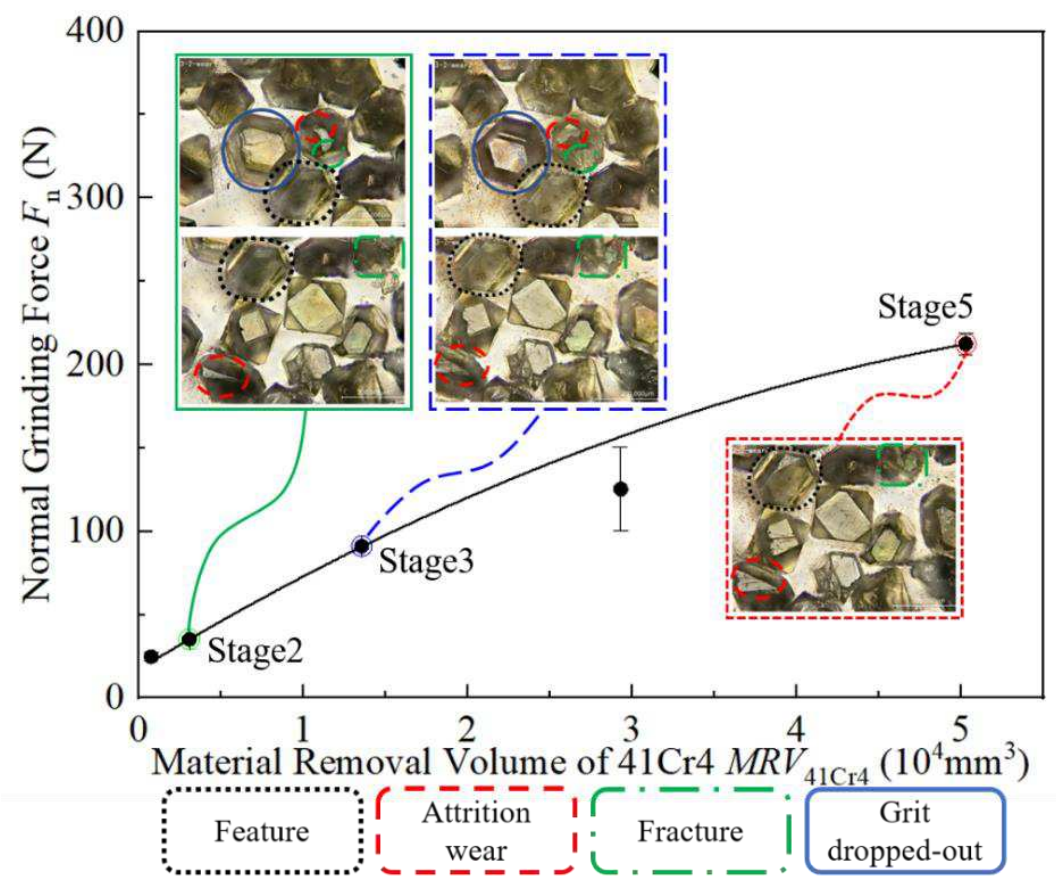

Fig. 2 Wheel topography and normal grinding force during different wear stages (Trial No. 2: $v_{\mathrm{s}}=500 \mathrm{rpm}$, $\left.v_{\mathrm{w}}=200 \mathrm{~mm} / \mathrm{min}, a_{\mathrm{p}}=100 \mu \mathrm{m}\right)$
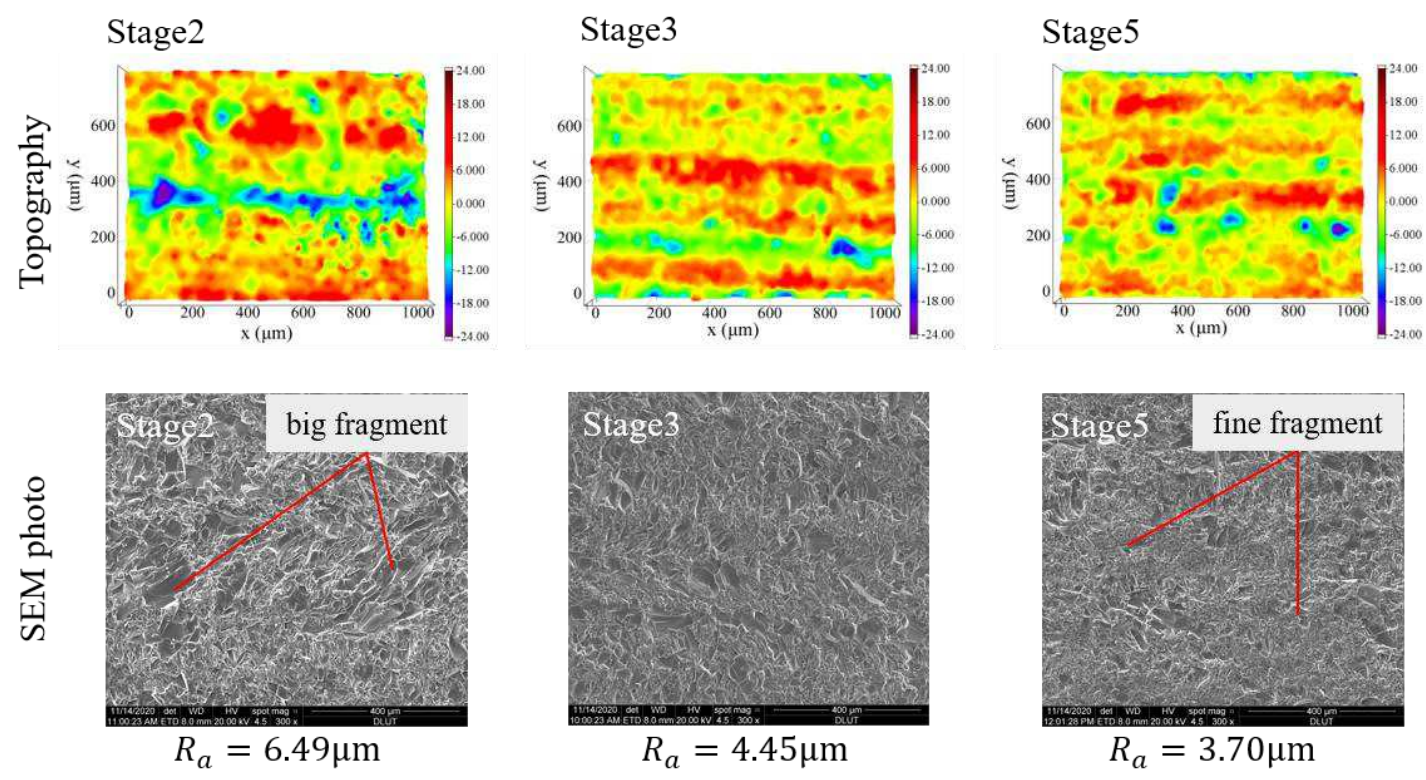

Fig.3 The topography and SEM photos of the ground surface (Trial No. 2: $v_{\mathrm{s}}=500 \mathrm{rpm}, v_{\mathrm{w}}=200 \mathrm{~mm} / \mathrm{min}$, $\left.a_{\mathrm{p}}=100 \mu \mathrm{m}\right)$ 
where $t_{\mathrm{m}}$ is the maximum undeformed chip thickness, $C$ is the number of cutting points per area, $r$ is the aspect ratio of the chip section, $V_{\mathrm{w}}$ is the infeed rate of the workpiece in $\mathrm{m} / \mathrm{s}, V_{\mathrm{s}}$ is the speed of grinding wheel in $\mathrm{m} / \mathrm{s}, A_{\mathrm{p}}$ is the nominal depth of cut in $\mathrm{m}, d_{\mathrm{e}}$ is the equivalent diameter of grinding wheel in $\mathrm{m}$.

Defining a grinding processing parameter-related factor $k=\left(\frac{V_{\mathrm{w}}}{V_{\mathrm{s}}}\right)^{\frac{1}{2}} A_{\mathrm{p}}^{\frac{1}{4}}$, then the maximum undeformed chip thickness is

$$
t_{\mathrm{m}}=k \cdot\left(\frac{6}{C r}\right)^{\frac{1}{2}} \cdot d_{\mathrm{e}}^{-\frac{1}{4}}
$$

The parameter $k$ is determined by three grinding parameters, which reflects the influence of processing parameters on the maximum undeformed chip thickness.
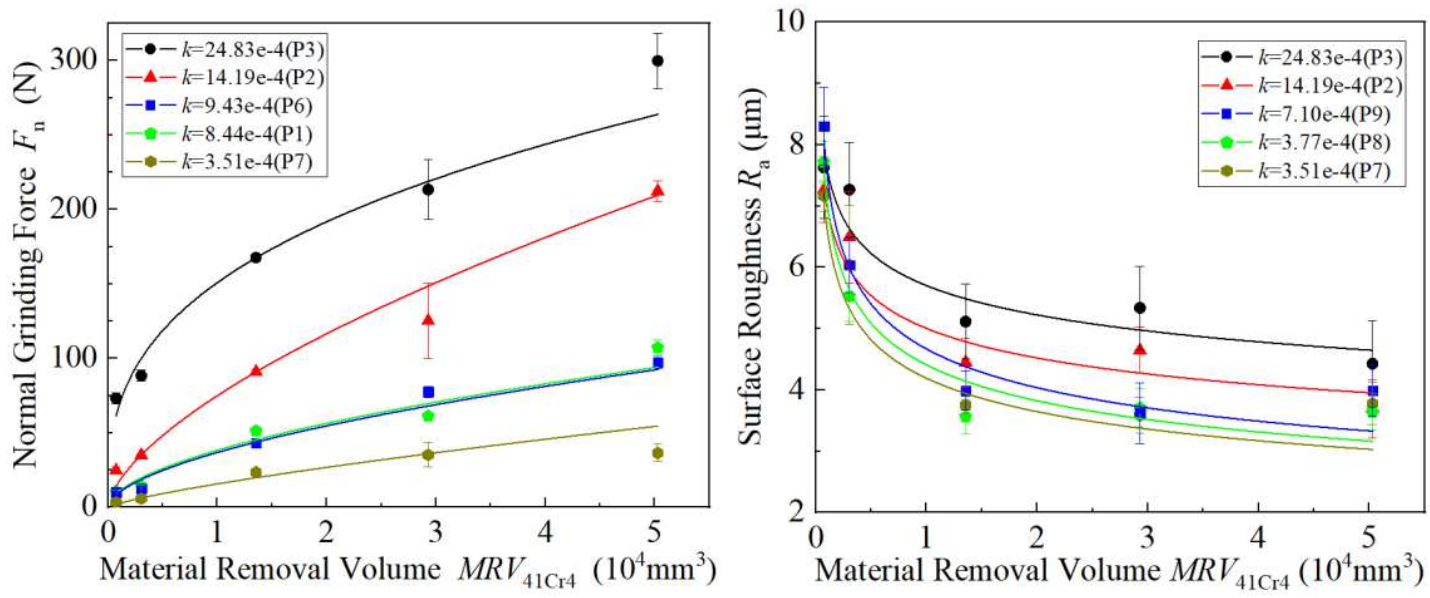

Fig. 4 The relationship between normal force $F_{\mathrm{n}}$, the surface roughness $R_{\mathrm{a}}$ and $M R V_{41 \mathrm{Cr} 4}$ under different processing parameters

The normal grinding force increases with the aggravation of grinding wheel wear and has a 
non-linear positive correlation with $M R V_{41 \mathrm{Cr} 4}$. On the contrary, the ground surface roughness has a non-linear negative correlation with $M R V_{41 \mathrm{Cr} 4}$. All nine groups of parameters show similar trends, as is shown in Fig. 4. Before stage 3, the normal grinding force increases rapidly, then, the normal grinding force increases slower as the wheel wear exasperates. On the opposite, the ground surface roughness decreases rapidly at first, then decreases slower as the wear aggravates. Therefore, the normal grinding force can be used to evaluate the wear state of the grinding wheel.

\subsection{The influences of wheel wear on existing surface roughness prediction models}

Roughness is an important characteristic parameter to evaluate the grinding quality. Surface roughness prediction models have attracted the attention of many scholars. Most researchers believe that the ground surface roughness is proportional to the undeformed chip thickness. The relationship is shown as Eq. (3) [14]

$$
E\left(R_{\mathrm{a}}\right)=0.396(1-f) E(t)
$$

where $E\left(R_{\mathrm{a}}\right)$ is the expected value of surface roughness $R_{\mathrm{a}}, f$ is the overlap factor, $E(t)$ is the expected value of undeformed chip thickness which obeys a Rayleigh distribution.

This model is in good agreement with experimental results when the ground surface roughness is between tens of nanometers and a few microns [34]. However, this model did not consider the effect of grits wear. Considered that the wheel wear changes the distribution of maximum undeformed chip thickness, the relationship needs further research.

Fig. 5 shows that the relationship between surface roughness $R_{\mathrm{a}}$ and parameter $k$ varies in different wheel wear stages. In the later stage of wear, when the height of abrasive grits tends to be the same and obeys a normal distribution, it shows a linear relationship. However, in the initial 
wear stage, the linear relationship does not hold.

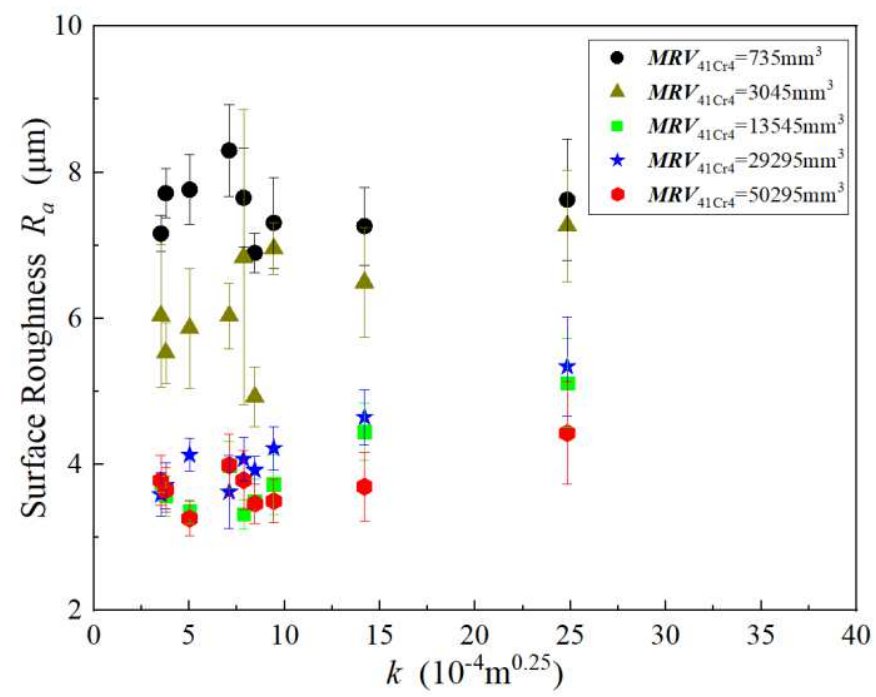

Fig. 5 The relationship between surface roughness $R_{\mathrm{a}}$ and parameter $k$ in different wear stages

In existing research, it shows that there is a certain relationship between grinding force and machined surface roughness [33], but few studies have quantified this relationship. The relationship among normal grinding force $F_{\mathrm{n}}$, parameter $k$, and surface roughness $R_{\mathrm{a}}$ is shown in Fig. 6. The data points are almost in a plane, showing a linear relationship among $F_{\mathrm{n}}, k$, and $R_{\mathrm{a}}$.

The relationship among normal grinding force $F_{\mathrm{n}}$, parameter $k$, and surface roughness $R_{\mathrm{a}}$ can be written as

$$
F_{\mathrm{n}}=a \cdot k+b \cdot R_{\mathrm{a}}+c
$$

where $a, b, c$ are the coefficients obtained by data fitting. The value of these coefficients and $R$ square (COD) is shown in Table 4. The R-square shows that the two-dimension linear relationship among $F_{\mathrm{n}}, k$, and $R_{\mathrm{a}}$ is valid. In addition, the value of the coefficient $a$ is positively related to $M R V_{41 \mathrm{Cr} 4}$, so $a$ can be used to indicate the degree of grinding wheel wear. 

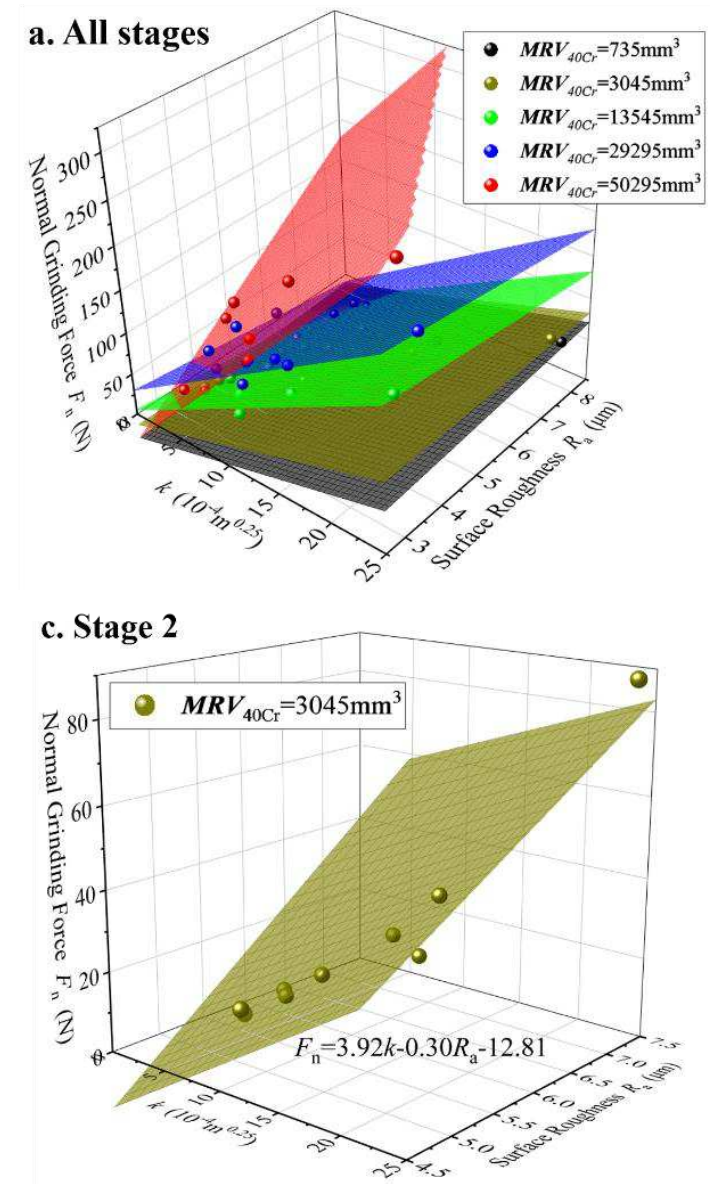

\section{e. Stage 4}

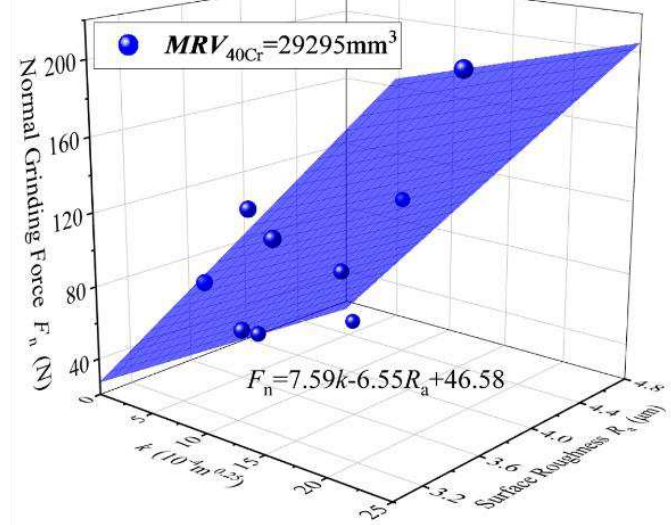

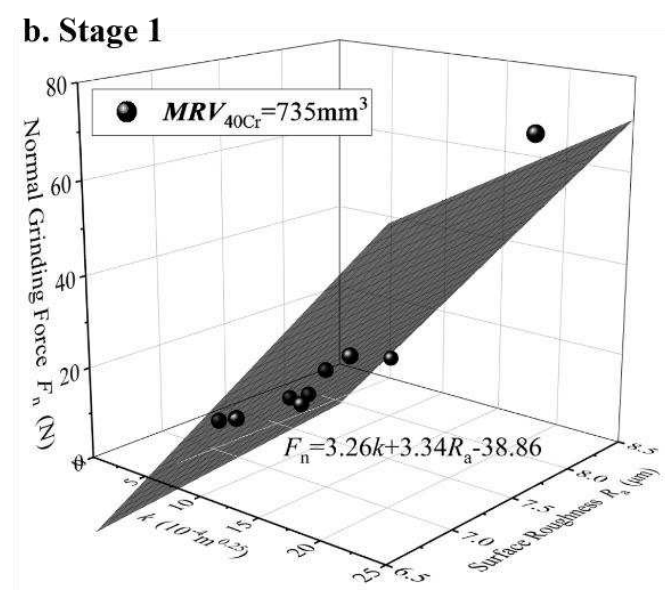

d. Stage 3

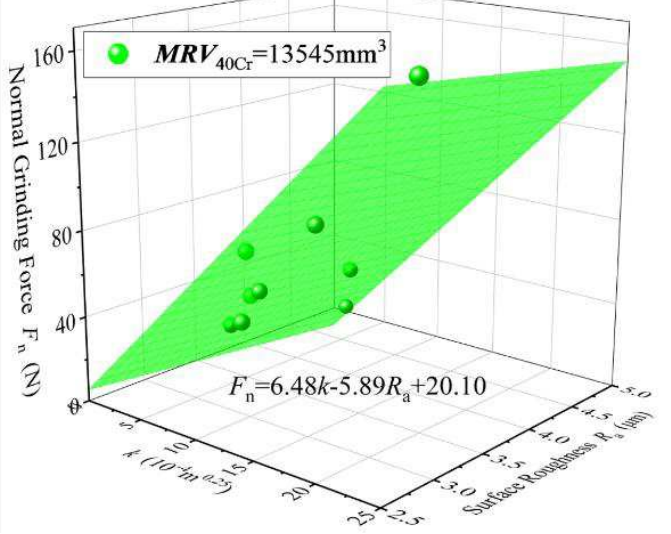

f. Stage 5

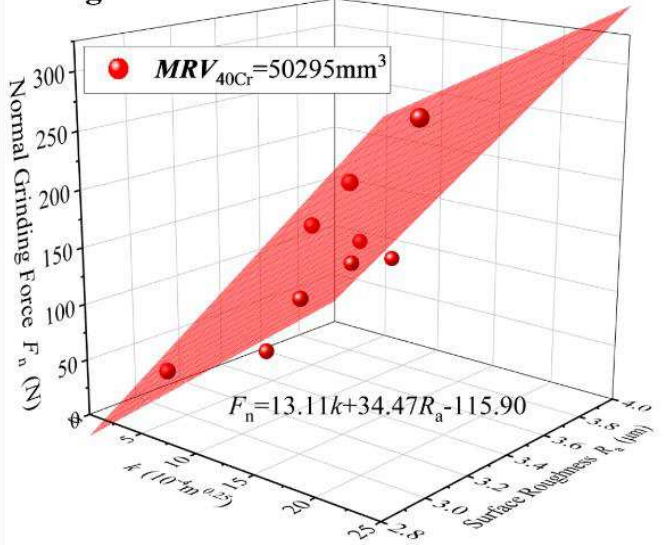

Fig. 6 The relationship among normal force $F_{\mathrm{n}}$, parameter $k$, and surface roughness $R_{\mathrm{a}}$ in different wear stages.

Data in (a) all stages, (b) stage 1, (c) stage 2, (d) stage 3, (e) stage 4, (f) stage 5

In conclusion, three sets of processing parameters can be selected for pre-experiment to determine the relationship among $F_{\mathrm{n}}, k$, and $R_{\mathrm{a}}$ which is only related to the wear state of grinding 
wheel. Then, the ground surface roughness $R_{\mathrm{a}}$ can be predicted by the normal grinding force $F_{\mathrm{n}}$ and parameter $k$ during the grinding process.

Table 4 The value of fitting coefficients and R-square in different wear stages

\begin{tabular}{cccccc}
\hline Factors & Stage1 & Stage2 & Stage3 & Stage4 & Stage5 \\
\hline$a$ & 3.26 & 3.92 & 6.48 & 7.59 & 13.11 \\
$b$ & 3.34 & -0.30 & -5.89 & -6.55 & 34.47 \\
$c$ & -38.85 & -12.81 & 20.10 & 46.58 & -115.90 \\
$R^{2}$ & 0.952 & 0.956 & 0.951 & 0.830 & 0.906 \\
\hline
\end{tabular}

\subsection{Sensitivity analysis}

In grinding process, as the wheel wear exacerbates, the surface roughness decreases. However, the grinding force increases with the wheel wear intensifies, which will increase the probability of surface quality instability. Therefore, the sensitivity analysis of the grinding process is helpful to ensure the stability of workpiece quality in a long-time grinding process.

\subsubsection{Sensitivity of surface roughness to grinding parameters}

When the grinding surface roughness fluctuates or deteriorates, it is necessary to adjust the processing parameters to ensure the ground surface roughness meets demand. Theoretically, adjusting any of the three parameters can achieve the goal, but priority should be given to adjusting the most sensitive parameter.

Table 5 shows the $F$ value from ANOVA of ground surface roughness $R_{a}$ in different wheel 
wear stages. From the $F$ distribution critical value table, three critical value is found that $F_{0.1}(2$, $8)=3.11, F_{0.05}(2,8)=4.45, F_{0.01}(2,8)=8.65$, and the significance is marked as '+', '++', '+++' respectively.

When grinding with a new grinding wheel, the effect of processing parameters on roughness is not obvious, as shown in Table 5. When the wheel wear reaches to stage 2, the workpiece infeed rate has a significant influence on the ground surface roughness. In stage 3 and stage 4, the wheel speed is the only parameter that has a significant influence. When it comes to stage 5, all the parameters have a great impact on ground surface roughness and the depth of cut is the primary significant parameter, followed by workpiece infeed rate. Therefore, in different wear stages, the operator should give priority to adjusting the most significant parameters to make the grinding quality meets the requirements.

Table 5 The $F$ value from ANOVA of surface roughness $R_{\text {a }}$

\begin{tabular}{c|ccccc}
\hline \multirow{2}{*}{ Factors } & \multicolumn{5}{c}{$F$ value } \\
\cline { 2 - 6 } & Stage 1 & Stage 2 & Stage 3 & Stage 4 & Stage 5 \\
\hline Wheel speed $v_{\mathrm{s}}$ & 0.95 & 1.49 & $3.89(+)$ & $3.67(+)$ & $9.09(+++)$ \\
Feed $v_{\mathrm{w}}$ & 0.95 & $4.19(+)$ & 2.76 & 0.98 & $14.53(+++)$ \\
Cutting depth $a_{\mathrm{p}}$ & 0.96 & 2.69 & 1.12 & 0.54 & $15.08(+++)$ \\
\hline
\end{tabular}

'+', ' ++ ', and ' +++ ' indicate the significance level of $F$ test is $0.1,0.05,0.01$, respectively. 


\subsubsection{Sensitivity of grinding force to grinding parameters and wheel wear}

The increase of normal grinding force will increase the subsurface damage and the deformation of low stiffness parts. Therefore, the sensitivity of normal grinding force to grinding parameters should be analyzed to guide the adjustment of grinding parameters to reduce the grinding force. Moreover, a long-term steady grinding state is beneficial to maintain the consistency of product quality. So, the sensitivity of normal grinding force to wheel wear should be studied to maintain the steady grinding state for a longer time.

Table 6 The $F$ value from ANOVA of the normal grinding force $F_{\mathrm{n}}$

\begin{tabular}{c|ccccc}
\hline \multirow{2}{*}{ Factors } & \multicolumn{5}{c}{$F$ value } \\
\cline { 2 - 6 } & Stage 1 & Stage 2 & Stage 3 & Stage 4 & Stage 5 \\
\hline Wheel speed $v_{\mathrm{s}}$ & $3.90(+)$ & $4.61(+)$ & $12.34(+++)$ & $9.76(+++)$ & $26.30(+++)$ \\
Feed $v_{\mathrm{w}}$ & 2.13 & 2.25 & $4.23(+)$ & $7.40(++)$ & $6.74(++)$ \\
Cutting depth $a_{\mathrm{p}}$ & 1.80 & 2.03 & $5.25(++)$ & $7.60(++)$ & $8.41(++)$ \\
\hline
\end{tabular}

'+', ' ++ ', and ' +++ ' indicate the significance level of $F$ test is $0.1,0.05,0.01$, respectively.

Table 6 shows the $F$ value from the ANOVA results of the normal grinding force indifferent wear stages. The results show that the grinding wheel speed has a remarkable influence on normal grinding force in all wear stages. Before stage 2 , wheel speed is the only parameter that significantly affects the normal grinding force. With the wheel wear further increases, the workpiece infeed rate and depth of cut show a significant influence on normal grinding force. In 
order to reduce the grinding force, the operator should first consider increasing the wheel speed, followed by the cutting depth.

In order to reduce the grinding force, the sensitivity of the grinding force to processing parameters was analyzed. To maintain the steady grinding state in a long-term grinding process, the sensitivity of grinding force to grinding wheel wear need to be further studied.

The change in normal grinding force is defined as

$$
\delta_{n, n+1}=\left|\frac{F_{n+1}-F_{n}}{F_{n}}\right|
$$

where $n$ and $n+1$ stand for different wheel wear stages, $n=1,2,3,4$.

Table 7 The change in normal grinding force $F_{\mathrm{n}}$ when the wheel wear exacerbates.

\begin{tabular}{ccccc}
\hline Trial No. & $\delta_{1,2}$ & $\delta_{2,3}$ & $\delta_{3,4}$ & $\delta_{4,5}$ \\
\hline 1 & $34.14 \%$ & $254.31 \%$ & $19.21 \%$ & $74.99 \%$ \\
2 & $41.48 \%$ & $159.40 \%$ & $37.61 \%$ & $69.49 \%$ \\
3 & $20.72 \%$ & $89.54 \%$ & $27.29 \%$ & $40.46 \%$ \\
4 & $75.52 \%$ & $462.50 \%$ & $106.15 \%$ & $29.46 \%$ \\
5 & $36.30 \%$ & $295.09 \%$ & $75.48 \%$ & $22.69 \%$ \\
6 & $22.04 \%$ & $249.83 \%$ & $79.06 \%$ & $25.09 \%$ \\
7 & $75.17 \%$ & $298.12 \%$ & $49.86 \%$ & $3.61 \%$ \\
9 & $45.57 \%$ & $202.31 \%$ & $80.47 \%$ & $1.93 \%$ \\
\hline
\end{tabular}


If $\delta_{n, n+l}$ is the smallest under a certain set of processing parameters when the grinding wheel wear increases, the grinding state determined by this set of parameters is called steady state. While sensitive state appears when $\delta_{n, n+1}$ is the biggest. Table 7 shows the change in normal grinding force $\delta_{n, n+1}$ as the wheel wear exacerbates. Then ANOVA on the change of $F_{\mathrm{n}}$ is carried out to determine the sensitive state and steady state. The result is shown in Fig. 7.

Fig. 7 shows that in early wear stage (before stage 2), the steady state of normal grinding force appears with the parameters that the grinding wheel speed is $1000 \mathrm{rpm}$, the workpiece feed rate is $500 \mathrm{~mm} / \mathrm{min}$, and the cutting depth is $50 \mu \mathrm{m}$. Then the steady state changes to the parameters that the grinding wheel speed is $1000 \mathrm{rpm}$, the workpiece feed rate is $500 \mathrm{~mm} / \mathrm{min}$, and the cutting depth is $150 \mu \mathrm{m}$ between stage 2 and stage 3 . As the wear of grinding wheel further increases, the steady state gradually moves to the parameters that the grinding wheel speed is $5000 \mathrm{rpm}$, the workpiece feed rate is $500 \mathrm{~mm} / \mathrm{min}$, and the cutting depth is $150 \mu \mathrm{m}$. The steady state is influenced by wheel wear. The mechanism of the influence of grinding wheel wear on the steady grinding state needs to be studied to deepen the understanding of the mechanism of grinding process.

In different wheel wear stages, the processing parameters that determine the steady grinding state are different, which means that the mechanism that affects the steady state is different during different wear stages. For a new grinding wheel, the protrusion height of abrasive grits is highly random, fewer effective abrasive grits are involved in grinding and it is difficult to accurately characterize it by a certain distribution. (stage 1), shown in Fig. 8 (a). Due to the high randomness of abrasive grits protrusion height, the processing parameters that determine the 
steady state in this wear stage have no general regularity. As the wear intensifies, the protrusion height of abrasive grits can be described by a specific distribution. In this state, the parameters that determine the steady grinding state begin to show regularity (after stage 2). The mechanism of the sensitivity of grinding force to wheel wear in early stages (stage 2 stage 3 ) and late stages (stage $4 \sim$ stage 5 ) need to be studied to deepen the understanding of grinding mechanism.

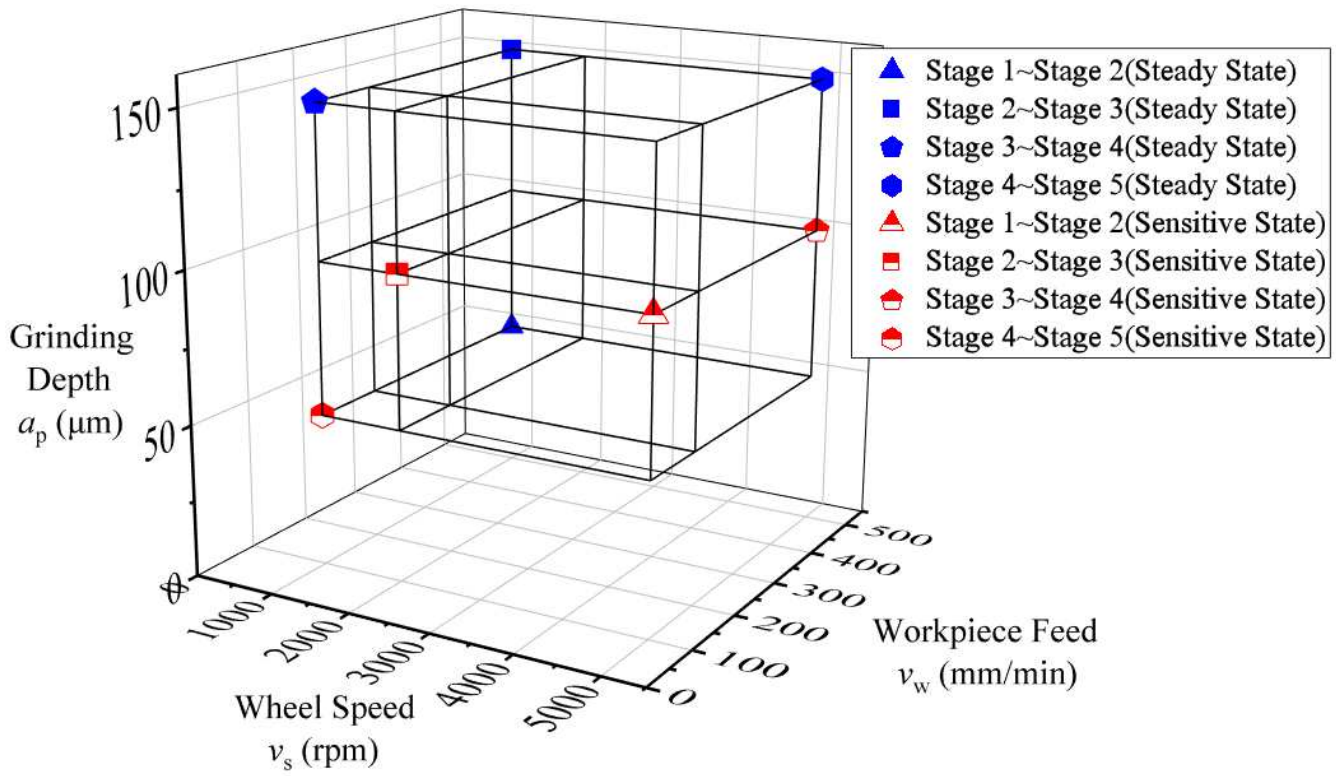

Fig. 7. The location of sensitive/steady state of grinding force in different wear stages.

When the grinding wheel is in early wear stages (stage $2 \sim$ stage 3 ), the number of effective abrasive grits involved in the grinding processing is less. Therefore, the reduction of abrasive grits protrusion height caused by grinding wheel wear $h_{\mathrm{w}}$ is significant, shown in Fig. 8. As a result, the grinding force generated by the parameters with a bigger actual cutting depth $a_{\mathrm{a}}$ is less sensitive to grinding wheel wear. Because the actual cutting depth $a_{\mathrm{a}}$ has a positive correlation with parameter $k$, so the relationship between $\delta_{n, n+l}$ and $a_{\text {a }}$ can be qualitatively described by the 
relationship between $\delta_{n, n+1}$ and $k$. As shown in Fig. 9, with the increase of parameter $k$, the grinding steady tends to be steady in early wheel wear stages (stage $2 \sim$ stage 3 ). It is consistent with the trend of experimental data analysis. However, when the wheel wear is severe (stage 4 stage 5), the trend from experimental analysis is contrary to this theory. So, the mechanism should be further studied.

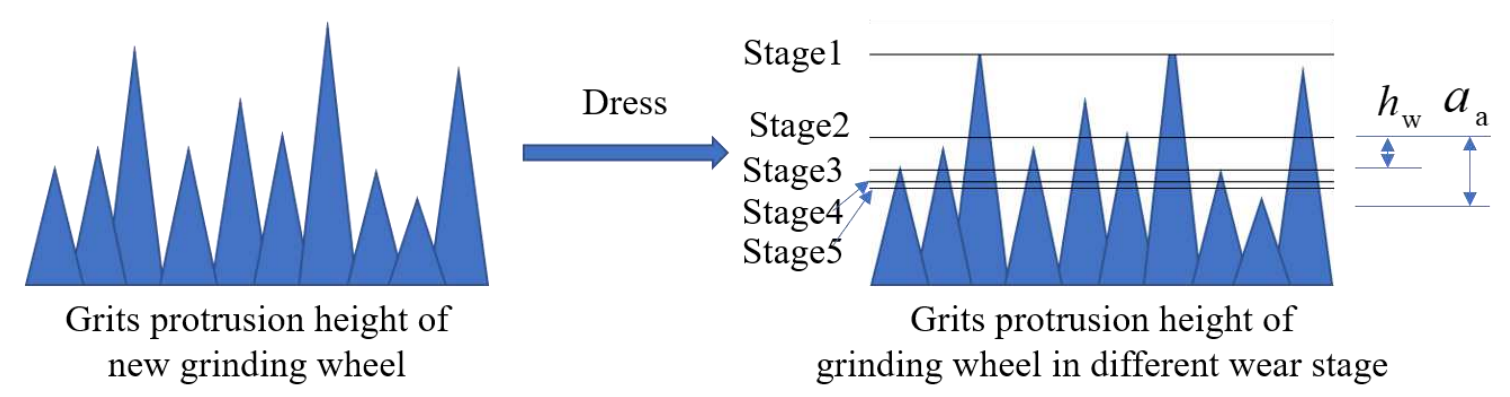

Fig. 8. The change of abrasive grit protrusion height in different wear stages.

As the wheel wear intensifies, the frictional force on the wear plane of abrasive grits becomes the main component of grinding force. The normal grinding force component is shown as Eq. (5) [31]

$$
f_{\mathrm{n}}=\frac{4 \cdot P_{0} \cdot S_{\mathrm{w}} \cdot N_{\mathrm{d}} \cdot V_{\mathrm{w}}}{D \cdot V_{\mathrm{s}}}
$$

where $P_{0}$ is a constant determined by experiment condition, $S_{\mathrm{w}}$ is the tip area of the worn grit, $N_{\mathrm{d}}$ is the number of dynamic active grits, $V_{\mathrm{w}}$ is the peripheral speed of grinding wheel in $\mathrm{m} / \mathrm{s}, D$ is the diameter of the grinding wheel, $V_{\mathrm{s}}$ is the feed speed in $\mathrm{m} / \mathrm{s}$. 


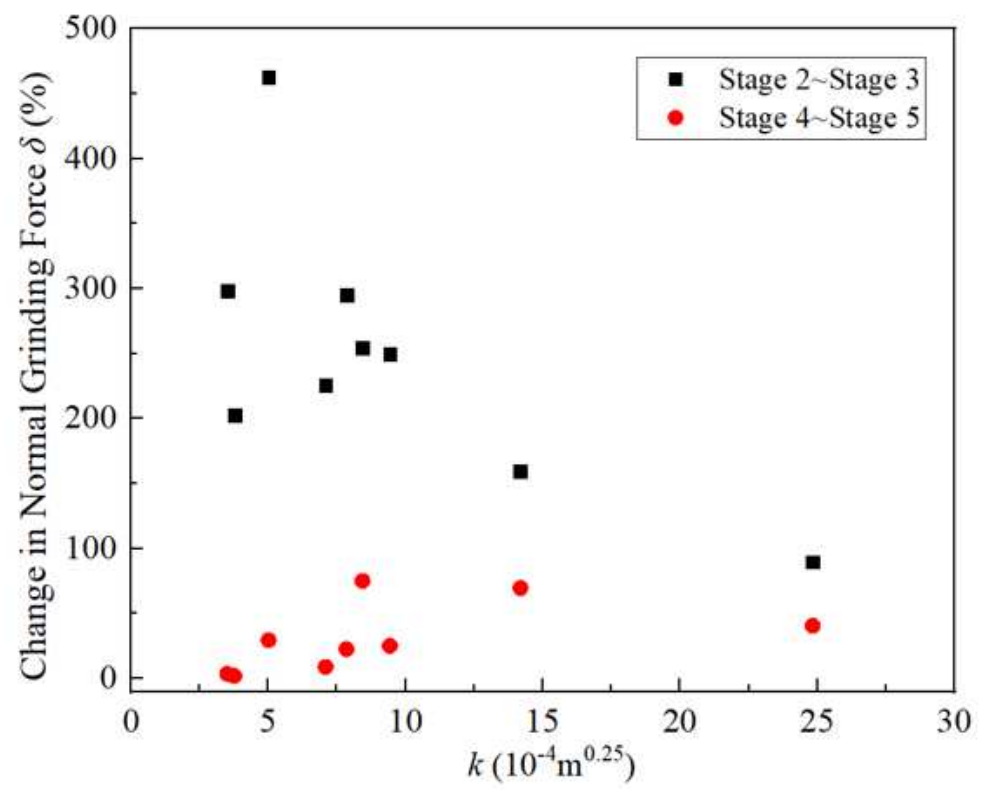

Fig. 9. The relationship between the change in normal force $\delta$ and $k$.

The wheel wear will cause variation in parameter $S_{\mathrm{w}}$ and $N_{\mathrm{d}}$. The total differential of $f_{\mathrm{n}}$ to the wheel wear $w$ can be expressed as Eq. (7). The partial derivatives of $f_{\mathrm{n}}$ with respect to $S_{\mathrm{w}}$ and $N_{\mathrm{d}}$ are also calculated to analyze the sensitivity of grinding normal force to wheel wear. Shown in Eq. (8) and Eq. (9). When the state of the grinding wheel is determined, the wear area $S_{\mathrm{w}}$ can be treated as a constant. So, $N_{\mathrm{d}} V_{\mathrm{w}} / V_{\mathrm{s}}$ and $V_{\mathrm{w}} / V_{\mathrm{s}}$ are the key parameters of influence on the sensitivity of $F_{\text {n }}$ to wheel wear.

$$
\begin{gathered}
\frac{\mathrm{d} f_{\mathrm{n}}}{\mathrm{d} w}=\frac{\partial f_{\mathrm{n}}}{\partial S_{\mathrm{w}}} \cdot \frac{\mathrm{d} S_{\mathrm{w}}}{\mathrm{d} w}+\frac{\partial f_{\mathrm{n}}}{\partial N_{\mathrm{d}}} \cdot \frac{\mathrm{d} N_{\mathrm{d}}}{\mathrm{d} w} \\
\frac{\partial f_{\mathrm{n}}}{\partial S_{\mathrm{w}}}=\frac{4 \cdot P_{0}}{D} \cdot \frac{N_{\mathrm{d}} \cdot V_{\mathrm{w}}}{V_{\mathrm{s}}} \\
\frac{\partial f_{\mathrm{n}}}{\partial N_{\mathrm{d}}}=\frac{4 \cdot P_{0} \cdot S_{\mathrm{w}}}{D} \cdot \frac{V_{\mathrm{w}}}{V_{\mathrm{s}}}
\end{gathered}
$$

The change in $f_{\mathrm{n}}\left(\mathrm{d} f_{\mathrm{n}}\right)$ has a positive correlation with $\delta_{n, n+l}$ because $f_{\mathrm{n}}$ is the main component 
of $F_{\mathrm{n}}$ when the wheel wear is severe. So, $N_{\mathrm{d}} V_{\mathrm{w}} / V_{\mathrm{s}}$ and $V_{\mathrm{w}} / V_{\mathrm{s}}$ will have an influence on $\delta_{n, n+1}$. Because $N_{\mathrm{d}}$ has a positive relationship with parameter $k$, the relationship between $\delta_{n, n+1}$ and $N_{\mathrm{d}} V_{\mathrm{w}} / V_{\mathrm{s}}$ can be qualitatively described by the relationship between $\delta_{n, n+l}$ and $k V_{\mathrm{w}} / V_{\mathrm{s}}$, shown in Fig. 10 (a), and the relationship between $\delta_{n, n+1}$ and $V_{\mathrm{w}} / V_{\mathrm{s}}$ is shown in Fig. 10 (b). The grinding state determined by parameters that have a smaller value of $k V_{\mathrm{w}} / V_{\mathrm{s}}$ and $V_{\mathrm{w}} / V_{\mathrm{s}}$ is less sensitive to the grinding wheel wear. This trend is confirmed by the experimental results.

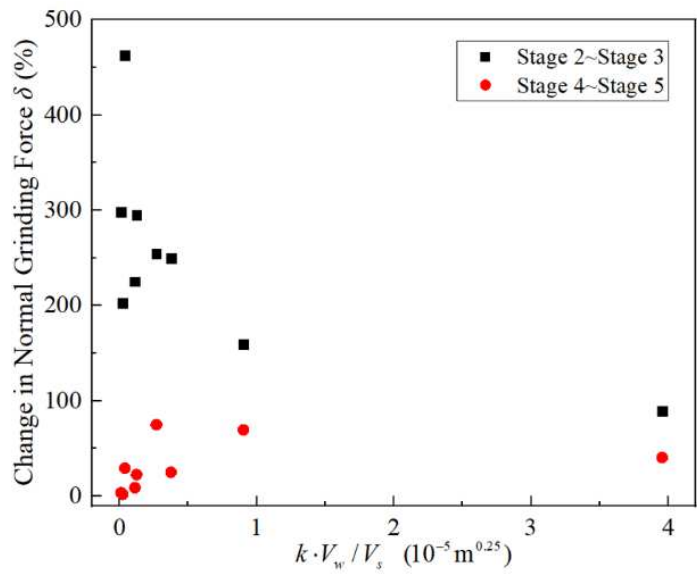

(a)

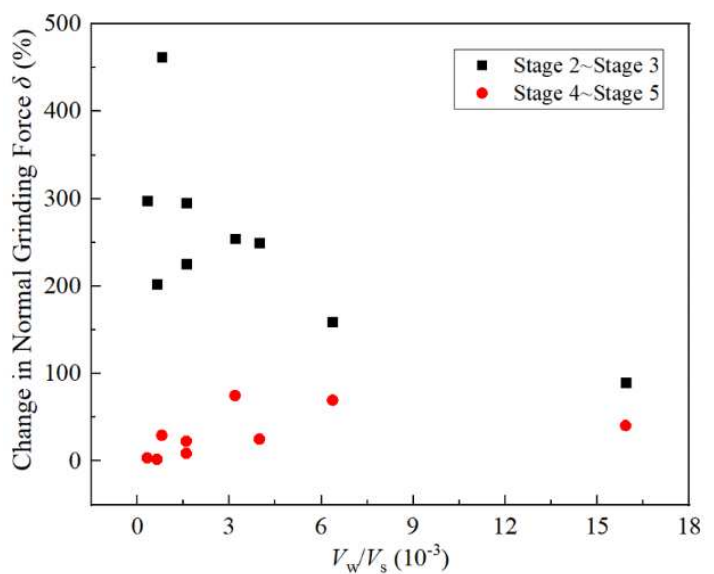

(b)

Fig. 10. The relationship between the change in normal force $\delta$ and (a) $k V_{\mathrm{w}} / V_{\mathrm{s}}$, (b) $V_{\mathrm{w}} / V_{\mathrm{s}}$.

Based on the above analysis, the operator should give priority to adjusting the most significant parameters towards the steady state to maintain the stability of grinding state. Benefit from this adjustment, the increase in the grinding force will be smaller when the grinding wheel continues to wear, and the stability of machining state and grinding quality can be maintained for a longer time, reducing the number of adjustments. 


\section{Conclusion}

In this paper, the influence of grinding wheel wear on grinding force and surface roughness is studied, and a semi-empirical roughness prediction model is proposed considering the influence of grinding wheel wear. To ensure the stability of the grinding process, sensitivity analysis was conducted to guide the adjustment of grinding parameters. Following conclusions are achieved:

(1) The normal grinding force can be used to evaluate the degree of grinding wheel wear. There is a non-linear positive relationship between the normal grinding force and material removal volume during grinding wheel accelerated wear treatment, while the surface roughness is the opposite.

(2) The capability of existing ground surface roughness prediction models is affected by the grinding wheel wear. The distribution of maximum undeformed chip thickness is changed in different wear status due to the change of abrasive grits protrusion height distribution. Consequently, the linear relationship between ground surface roughness and maximum undeformed chip thickness also changes due to the wheel wear.

(3) There is a linear relationship among the normal grinding force $F_{\mathrm{n}}$, parameter $k$, and surface roughness $R_{\mathrm{a}}$. The coefficient $a$ of the parameter $k$ can be used to indicate the degree of the grinding wheel wear. The equation among $F_{\mathrm{n}}, k$, and $R_{\mathrm{a}}$ can be determined by three preexperiments and the equation is only related to the wear state of the grinding wheel. Then, the ground surface roughness $R_{\mathrm{a}}$ can be predicted based on the normal force $F_{\mathrm{n}}$ and the parameter $k$. 
(4) Sensitivity analysis is conducted to guide the adjustment of grinding parameters. In different wear stage, the operator should give priority to adjusting the most significant parameters to meet the demand surface roughness. In order to maintain the stability of grinding state, preferred adjustment is given to reduce the grinding force and make the change in grinding force smaller.

Acknowledgments All authors appreciate the financial support from the National Natural Science Foundation of China (51875078, 51991372, 51975094), and the Science Fund for Creative Research Groups of NSFC of China (51621064).

Ethics approval This article has not been published or submitted elsewhere.

Consent to participate The authors consent to participate.

Consent for publication The authors consent to publish.

Author contribution Yonghao Wang: Conceptualization, Data curation, Writing - original draft. Ping Zhou: Project administration, Funding acquisition, Conceptualization, Writing - review \& editing. Yuhang Pan: Investigation, Writing - review \& editing. Ying Yan: Visualization. Dongming Guo: Visualization, Funding acquisition. 
Funding National Natural Science Foundation of China (Grant nos. 51875078, 51991372 and 51975094), and Science Fund for Creative Research Groups of NSFC of China (Grant nos. $51621064)$.

Competing interests The authors declare no competing interests.

Availability of data and materials The authors confirm that the data and materials supporting the findings of this study are available within the article.

\section{References:}

[1] H. Li, D. Axinte (2017) On a stochastically grain-discretised model for 2D/3D temperature mapping prediction in grinding. Int. J. Mach. Tools Manuf 116: 60-76. https://doi.org/10.1016/j.ijmachtools.2017.01.004

[2] S. Malkin, C. Guo (2008) Grinding Technology: Theory and Applications of Machining with Abrasives, second ed. Industrial Press, New York

[3] A. M. Tahvilian, Z. Liu, H. Champliaud, et al (2015) Characterization of grinding wheel grain topography under different robotic grinding conditions using confocal microscope. Int. J. Adv. Manuf. Technol 80: 1159-1171. https://doi.org/10.1007/s00170-015-7109-z

[4] A. Esmaeilzare, A. Rahimi, S. M. Rezaei (2014) Investigation of subsurface damages and surface roughness in grinding process of Zerodur glass-ceramic. Appl. Surf. Sci 313: 67-75. https://doi.org/10.1016/j.apsusc.2014.05.137 
[5] C. Wu, B. Li, Y. Liu, et al (2017) Surface roughness modeling for grinding of Silicon Carbide ceramics considering co-existence of brittleness and ductility. Int. J. Mech. Sci 133: 167177. https://doi.org/10.1016/j.ijmecsci.2017.07.061

[6] C. Zhu, P. Gu, Y. Wu, et al (2019) Surface roughness prediction model of SiCp/Al composite in grinding. Int. J. Mech. Sci 155: 98-109. https://doi.org/10.1016/j.ijmecsci.2019.02.025

[7] M. Seeman, G. Ganesan, R. Karthikeyan, et al (2010) Study on tool wear and surface roughness in machining of particulate aluminum metal matrix composite-response surface methodology approach. Int. J. Adv. Manuf. Technol 48: 613-624. https://doi.org/10.1007/s00170-009-2297-z

[8] W. Liu, Z. Deng, Y. Shang, et al (2017) Effects of grinding parameters on surface quality in silicon nitride grinding. Ceram. Int 43: 1571-1577. https://doi.org/10.1016/j.ceramint.2016.10.135

[9] S. Öztürk, M. F. Kahraman (2019) Modeling and optimization of machining parameters during grinding of flat glass using response surface methodology and probabilistic uncertainty analysis based on Monte Carlo simulation. Measurement 145: 274-291. https://doi.org/10.1016/j.measurement.2019.05.098

[10] Y. Sahin, A. R. Motorcu (2005) Surface roughness model for machining mild steel with $\begin{array}{lllll}\text { coated } & \text { carbide } & \text { 321-326. }\end{array}$ https://doi.org/10.1016/j.matdes.2004.06.015

[11] A. Saravanakumar, S. Dhanabal, E. Jatanand, et al (2018) Analysis of process parameters in surface grinding process. Mater. Today Proc 5: 8131-8137. https://doi.org/10.1016/j.matpr.2017.11.500 
[12] S. Agarwal (2016) Optimizing machining parameters to combine high productivity with high surface integrity in grinding silicon carbide ceramics. Ceram. Int 42: 6244-6262. http://dx.doi.org/10.1016/j.ceramint.2016.01.008

[13] Y. Pan, Y. Wang, P. Zhou, et al (2020) Activation functions selection for BP neural network model of ground surface roughness. J. Intell. Manuf. https://doi.org/10.1007/s10845-020$01538-5$

[14] S. Agarwal, P. V. Rao (2010) Modeling and prediction of surface roughness in ceramic grinding. Int. J. Mach. Tools Manuf 50: 1065-1076. https://doi.org/10.1016/j.ijmachtools.2010.08.009

[15] S. K. Khare, S. Angrwal (2015) Predictive modeling of surface roughness in grinding. Procedia CIRP 31: 375-380. https://doi.org/10.1016/j.procir.2015.04.092

[16] J. Sun, P. Chen, F. Qin, et al (2018) Modeling and experimental study of roughness in silicon wafer self-rotating grinding. Precis. Eng 51: 625-637. https://doi.org/10.1016/j.precisioneng.2017.11.003

[17] Y. Liu, A. Warkentin, R. Bauer, et al (2013) Investigation of different grain shapes and dressing to predict surface roughness in using kinematic simulations. Precis. Eng 37: 758764. http://dx.doi.org/10.1016/j.precisioneng.2013.02.009

[18] L. Zhou, Y. Ebina, K. Wu, et al (2017) Theoretical analysis on effects of grain size variation. Precis. Eng 50: 27-31. http://dx.doi.org/10.1016/j.precisioneng.2017.04.010

[19] Y. Novoselov, S. Bratan, V. Bogutsky (2016) Analysis of relation between grinding wheel wear and abrasive grains wear. Procedia Eng 150: 809-814. http://dx.doi.org/10.1016/j.proeng.2016.07.116 
[20] Q. Zhang, Q. Zhao, S. To, et al (2017) Diamond wheel wear mechanism and its impact on the surface generation in parallel diamond grinding of RB-SiC/Si. Diam. Relat. Mater 74: 16-23. http://dx.doi.org/10.1016/j.diamond.2017.01.019

[21] S. Jeon, A. Zolfaghari, C. Lee (2018) Dicing wheel wear monitoring technique utilizing edge $\begin{array}{llll}\text { diffraction } & \text { effect. } & \text { Measurement } & 121:\end{array}$ https://doi.org/10.1016/j.measurement.2018.02.057

[22] D. N. Naik, N. T. Mathew, L. Vijayaraghavan (2019) Wear of electroplated super abrasive CBN wheel during grinding of Inconel 718 super alloy. J. Manuf. Process 43: 1-8. https://doi.org/10.1016/j.jmapro.2019.04.033

[23] P. Sutowski, S. Plichta (2006) An investigation of the grinding wheel wear with the use of root-mean-square value of acoustic emission. Arch. Civ. Mech. Eng 6 (1): 87-98. https://doi.org/10.1016/S1644-9665(12)60078-8

[24] J. Badger, S. Murphy, G. E. O’Donnell (2018) Acoustic emission in dressing of grinding wheels: AE intensity, dressing energy, and quantification of dressing sharpness and increase in diamond wear-flat size. Int. J. Mach. Tools Manuf 125: 11-19. https://doi.org/10.1016/j.ijmachtools.2017.11.007

[25] A. Arun, K. Rameshkumar, D. Unnikrishnan, et al (2018) Tool condition monitoring of cylindrical grinding process using acoustic emission sensor. Mater. Today: Proc 5: 11888 11899. https://doi.org/10.1016/j.matpr.2018.02.162

[26] B. He, C. Wei, S. Ding, et al (2019) A survey of methods for detecting metallic grinding burn. Measurement 134: 426-439. https://doi.org/10.1016/j.measurement.2018.10.093

[27] P. S. Krishnan, K. Rameshkumar (2020) Grinding wheel condition prediction with discrete hidden Markov model using acoustic emission signature. Mater. Today Proc https://doi.org/10.1016/j.matpr.2019.12.428 
[28] B. Varghese, S. Pathare, R. Gao, et al (2000) Development of a sensor-integrated "intelligent" grinding wheel for in-process monitoring. Ann. CIRP 49 (1): 231-234. https://doi.org/10.1016/S0007-8506(07)62935-7

[29] D. Nguyen, S. Yin, Q. Tang, et al (2019) Online monitoring of surface roughness and grinding wheel wear when grinding Ti-6Al-4V titanium alloy using ANFIS-GPR hybrid algorism and Taguchi analysis. Precis. Eng 55: 275-292. https://doi.org/10.1016/j.precisioneng.2018.09.018

[30] K. Kannan, N. Arunachalam (2018) Grinding wheel redress life estimation using force and $\begin{array}{lllll}\text { surface texture } & \text { analysis. }\end{array}$ https://doi.org/10.1016/j.procir.2018.03.031

[31] Y. Zhang, C. Li, H. Ji, et al (2017) Analysis of grinding mechanics and improved prediction force model based on material-removal and plastic-stacking mechanisms. Int. J. Mach. Tools Manuf 122: 81-97. http://dx.doi.org/10.1016/j.ijmachtools.2017.06.002

[32] D. P. Selvaraj, P. Chandramohan, M. Mohanraj (2014) Optimization of surface roughness, cutting force and tool wear of nitrogen alloyed duplex stainless steel in a dry turning process $\begin{array}{llll}\text { using } & \text { Taguchi } & \text { 205-215. }\end{array}$ http://dx.doi.org/10.1016/j.measurement.2013.11.037

[33] D. Zhu, X. Xu, Z. Yang, et al (2018) Analysis and assessment of robotic belt grinding mechanism by force modeling and force control experiment. Tribol. Int 120: 93-98. https://doi.org/10.1016/j.triboint.2017.12.043

[34] W. Ding, C. Dai, T. Yu, et al (2017) Grinding performance of textured monolayer CBN wheels: Undeformed chip thickness nonuniformity modeling and ground surface topography $\begin{array}{lllll}\text { prediction. } & \text { Int. } & \text { J. Mach. Tools } & \text { Manuf } & \text { 122: }\end{array}$ http://dx.doi.org/10.1016/j.ijmachtools.2017.05.006 


\section{Figure captions list}

Fig. 1 shows the schematic diagram of the grinding experiment setup. The normal grinding force was measured during grinding process with a piezoelectric dynamometer Kistler 9139 AA2 and the ground surface roughness was measured by a profilometer Talysurf CLI2000

Fig. 2 shows wheel topography and normal grinding force in different wear stages with the grinding parameters: $v_{\mathrm{s}}=500 \mathrm{rpm}, v_{\mathrm{w}}=200 \mathrm{~mm} / \mathrm{min}, a_{\mathrm{p}}=100 \mu \mathrm{m}$. In stage 2 , the attrition wear of abrasive grits was observed. As the wear intensified, the attrition wear of abrasive grits gradually exacerbated, the abrasive grits fracture and dropped-out occurred in stage 3 . When it comes to stage 5 , the abrasive wear was further aggravated, shown as big attrition wear area Fig. 3 shows the topography and SEM photos of the ground surface in different wear stages with the grinding parameters: $v_{\mathrm{s}}=500 \mathrm{rpm}, v_{\mathrm{w}}=200 \mathrm{~mm} / \mathrm{min}, a_{\mathrm{p}}=100 \mu \mathrm{m}$. In stage 2 , obvious groove marks and significant material fragmentation were also observed on the ground surface. In stage 3 , the material was broken into finer pieces. In stage 5 , the grinding surface tended to be flat and the fragment became finer

Fig. 4 shows the relationship between normal force $F_{\mathrm{n}}$, the surface roughness $R_{\mathrm{a}}$ and $M R V_{41 \mathrm{Cr} 4}$ under different processing parameters. The normal grinding force increases with the aggravation of grinding wheel wear and has a non-linear positive correlation with $M R V_{41 \mathrm{Cr} 4}$. On the contrary, the ground surface roughness has a non-linear negative correlation with $M R V_{41 \mathrm{Cr} 4}$. All nine groups of parameters show similar trends. Before stage 3, the grinding force increases rapidly, then, the grinding force increases slower as the wear exasperates. On the opposite, roughness decreases rapidly at first, then increases slowly as the wear aggravates 
Fig. 5 shows the relationship between surface roughness $R_{\mathrm{a}}$ and parameter $k$ in different wear stages. In the later stage of wear, it shows a linear relationship (green square, blue five-pointed star, red hexagon). However, in the initial wear stage, the linear relationship does not hold (black circle, brown triangle)

Fig. 6 shows the relationship among normal force $F_{\mathrm{n}}$, parameter $k$, and surface roughness $R_{\mathrm{a}}$ in different wear stages. In all stages, the data points are almost in a plane, showing a twodimension linear relationship among $F_{\mathrm{n}}, k$, and $R_{\mathrm{a}}$

Fig. 7 shows the location of parameters that determine the sensitive/steady state of grinding force in different wear status. The red symbol stands for sensitive state and the blue symbol stands for steady state. In the early stage of grinding wheel wear (before stage 2), the steady parameters of grinding force appear when the grinding wheel speed is $1000 \mathrm{rpm}$, the workpiece feed rate is $500 \mathrm{~mm} / \mathrm{min}$, and the cutting depth is $50 \mu \mathrm{m}$. As the wear of the grinding wheel increases, the steady parameters gradually move to the parameters that the grinding wheel speed is $5000 \mathrm{rpm}$, the workpiece feed rate is $500 \mathrm{~mm} / \mathrm{min}$, and the cutting depth is $150 \mu \mathrm{m}$

Fig. 8 shows the change of abrasive grit protrusion height in different wear stages. Before stage 3, the number of effective abrasive grits involved in the grinding processing is less. Therefore, the reduction of abrasive grits protrusion height caused by grinding wheel wear $h_{\mathrm{w}}$ is significant. As a result, the grinding force generated by the parameters with a bigger actual cutting depth aa is less sensitive to grinding wheel wear

Fig. 9 shows the relationship between $\delta$ and $k$. With the increase of parameter $k$, the grinding state tends to be steady in early wheel wear stages (stage 2 stage 3 ). It is consistent with the 
trend of experimental data analysis. However, when the wheel wear is severe (stage 4 stage 5), the trend from experimental analysis is contrary to this theory

Fig. 10 shows the relationship between the change in normal force $\delta$ and $k V_{\mathrm{w}} / V_{\mathrm{s}}$ (Fig. 10 (a)), $V_{\mathrm{w}} / V_{\mathrm{s}}$ (Fig. $\left.10(\mathrm{~b})\right)$. The grinding state determined by parameters that have a smaller value of $k V_{\mathrm{w}} / V_{\mathrm{s}}$ and $V_{\mathrm{w}} / V_{\mathrm{s}}$ is less sensitive to the grinding wheel wear. This trend is confirmed by the experimental results 


\section{Table captions list}

Table 1 shows the properties of the quartz workpiece used in the experiment

Table 2 shows the process control parameters and their range in the experiment

Table 3 shows the experiment parameters and the normal grinding force $F_{\mathrm{n}}$ during grinding process, Ra value of the ground surface in different wear stages

Table 4 shows the values of fitting coefficients $a, b, c$ in Eq. (3) and their R-square in different wear stages. The R-square shows that the two-dimension linear relationship among grinding force $F_{\mathrm{n}}$, parameter $k$, and surface roughness $R_{\mathrm{a}}$ is valid. In addition, the value of the coefficient $a$ is positively related to $M R V_{41 \mathrm{Cr} 4}$, so coefficient a can be used to indicate the degree of grinding wheel wear

Table 5 shows the $F$ value from ANOVA of the normal grinding force $R_{\mathrm{a}}$ in different wear stages. The symbol '+', '++', and ' +++ ' indicate the significance level of $F$ test is $0.1,0.05,0.01$, respectively. When grinding with a new grinding wheel, the effect of processing parameters on roughness is not obvious. When the wheel wear reaches to stage 2 , the workpiece infeed rate has a significant influence on the ground surface roughness. In stage 3 and stage 4 , the wheel speed is the only parameter that has a significant influence. When it comes to stage 5 , all the parameters have a great impact on ground surface roughness and the depth of cut is the primary significant parameter, followed by workpiece infeed rate

Table 6 shows the $F$ value from the ANOVA results of the normal grinding force indifferent wear stages. The results show that the grinding wheel speed has a remarkable influence on normal grinding force in all wear stages. Before stage 2, wheel speed is the only parameter that 
significantly affects the normal grinding force. With the wheel wear further increases, the workpiece infeed rate and depth of cut show a significant influence on normal grinding force Table 7 shows the change in normal grinding force $F_{\mathrm{n}}$ when the wheel wear exacerbates. The ANOVA was conducted based on these data to analyze the sensitivity of grinding normal force to wheel wear 
Figures

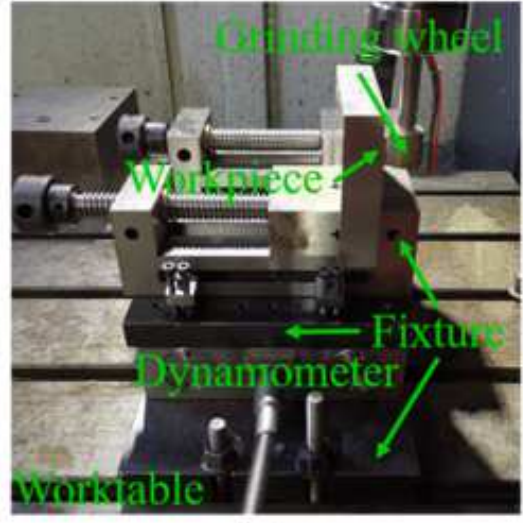

(a)

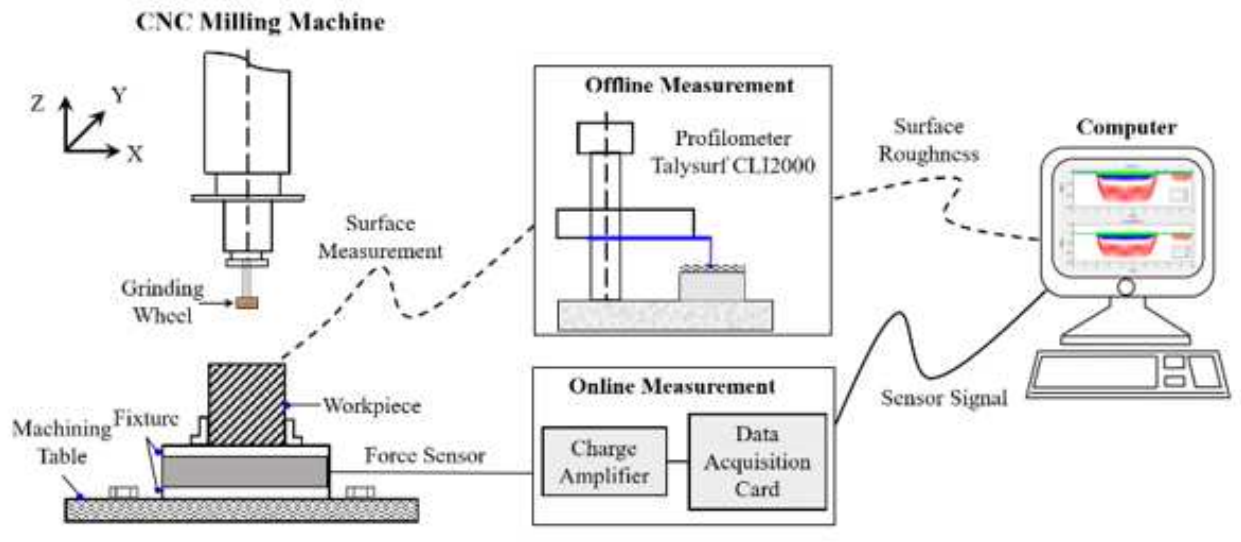

(b)

Figure 1

Schematic diagram of the grinding experiment setup 


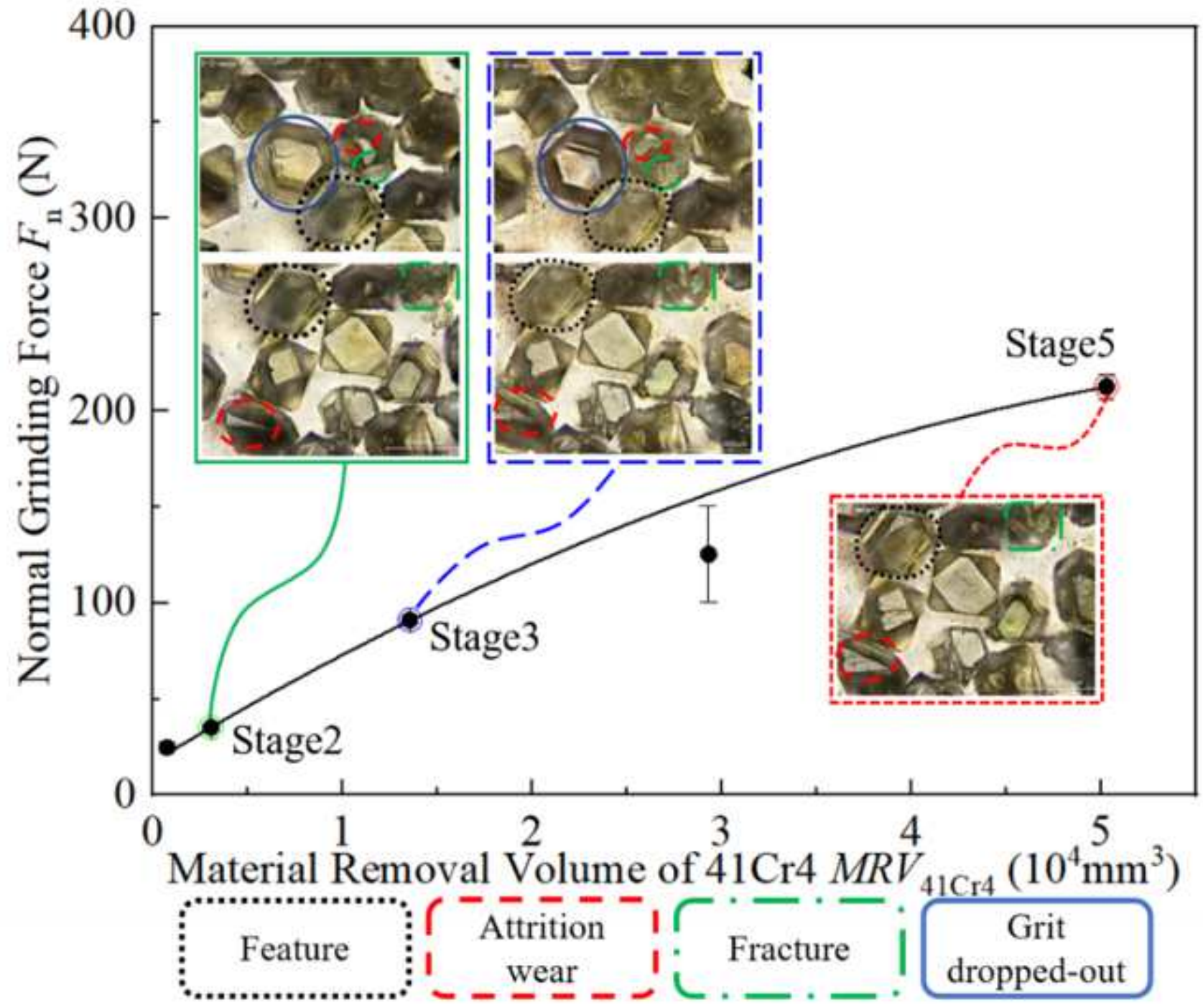

Figure 2

Wheel topography and normal grinding force during different wear stages (Trial No. 2: vs=500rpm, $\mathrm{vw}=200 \mathrm{~mm} / \mathrm{min}, \mathrm{ap}=100 \mu \mathrm{m})$ 
Stage 2
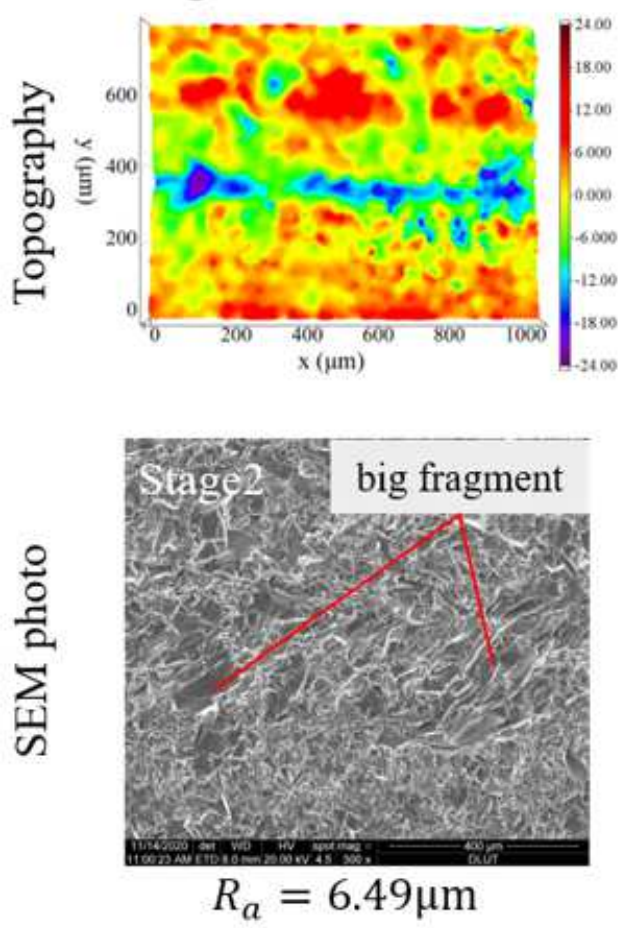

Stage3
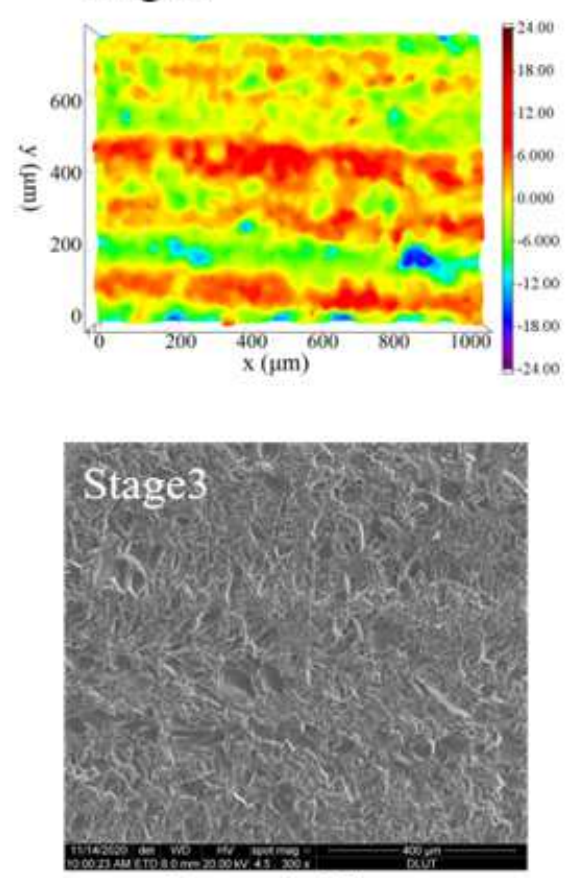

$R_{a}=4.45 \mu \mathrm{m}$
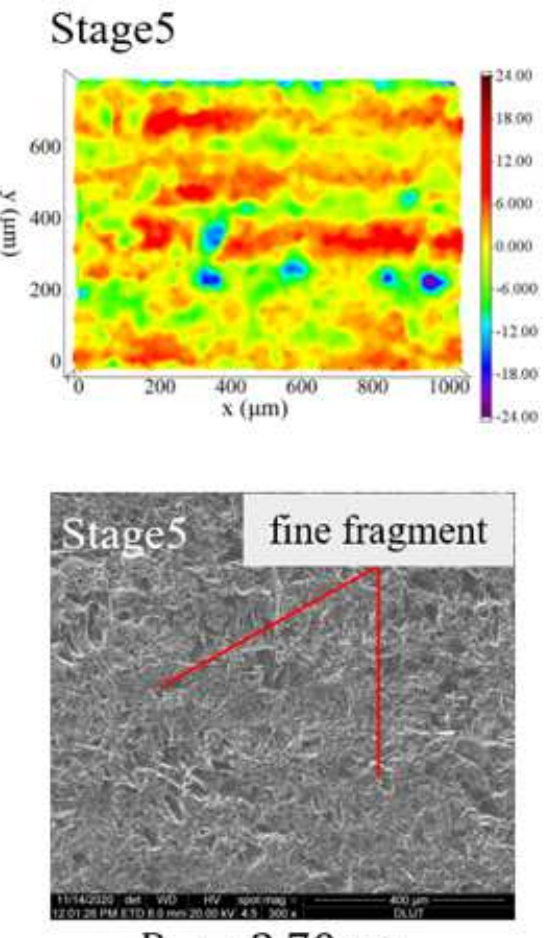

$R_{a}=3.70 \mu \mathrm{m}$

\section{Figure 3}

The topography and SEM photos of the ground surface (Trial No. 2: vs $=500 \mathrm{rpm}, \mathrm{vw}=200 \mathrm{~mm} / \mathrm{min}$, ap $=100 \mu \mathrm{m})$
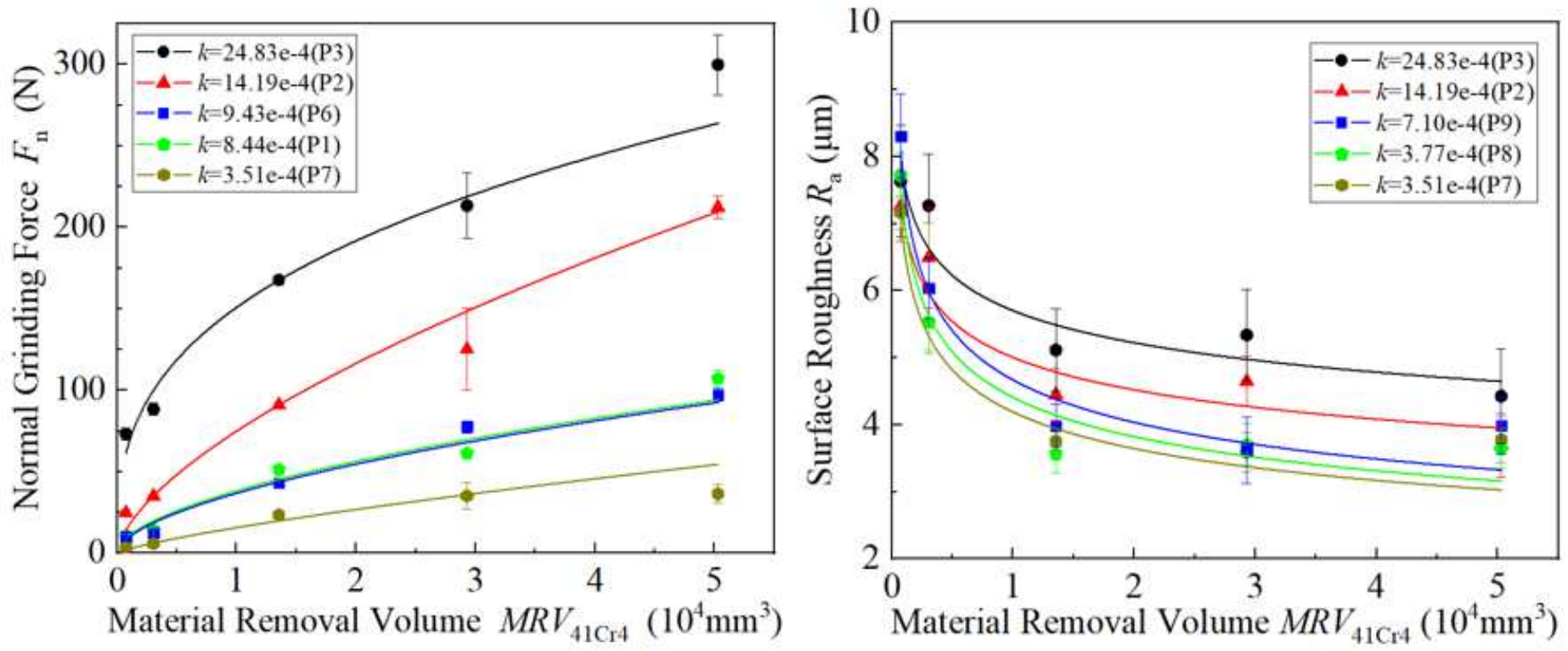

Figure 4

The relationship between normal force $\mathrm{Fn}$, the surface roughness $\mathrm{Ra}$ and MRV41Cr4 under different processing parameters 


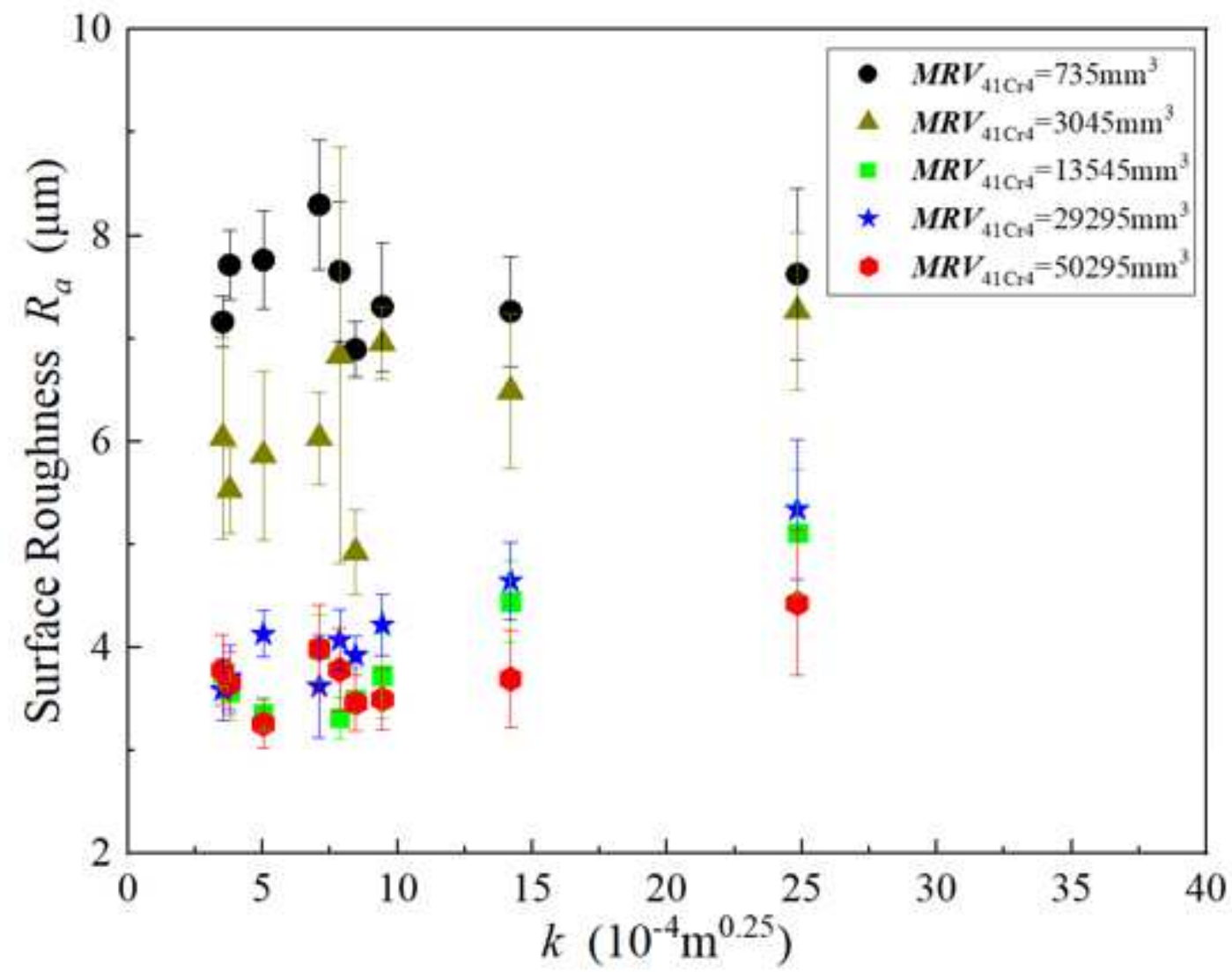

Figure 5

The relationship between surface roughness $\mathrm{Ra}$ and parameter $\mathrm{k}$ in different wear stages 


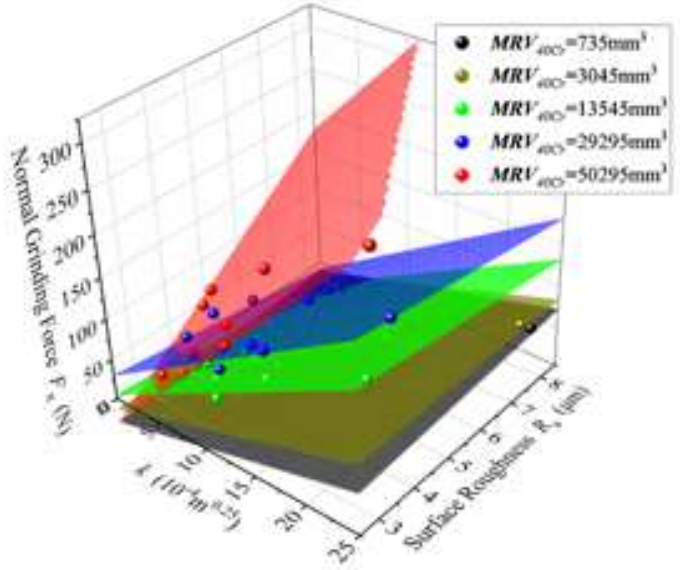

(a)

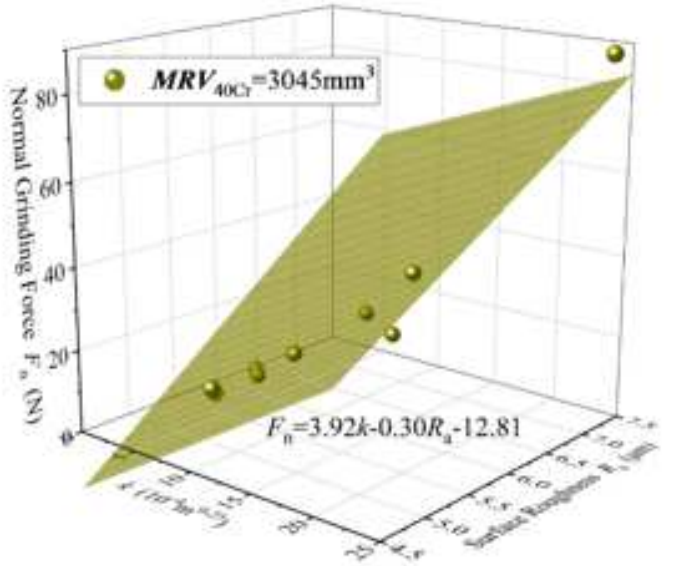

(c)

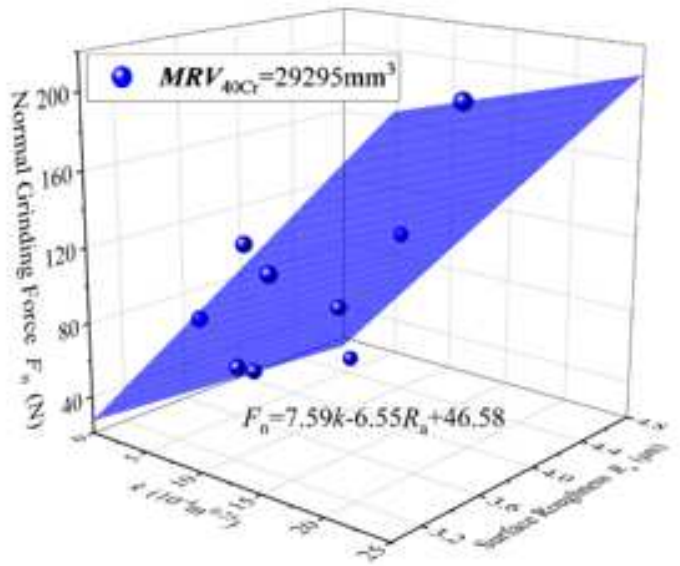

(e)

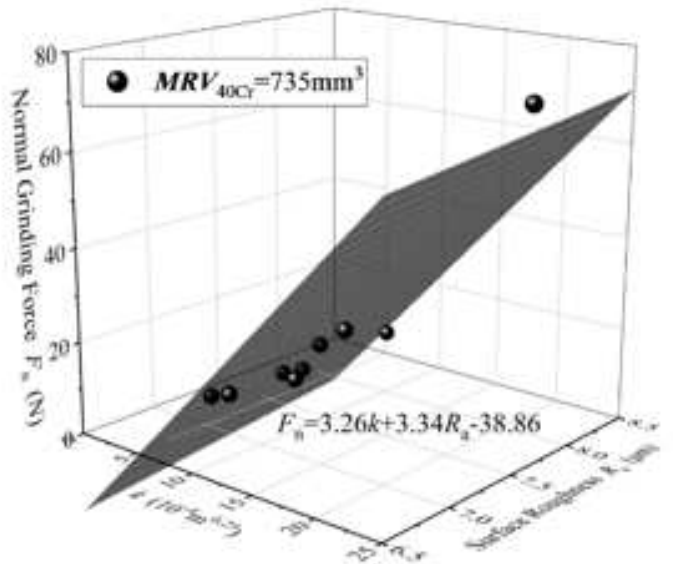

(b)

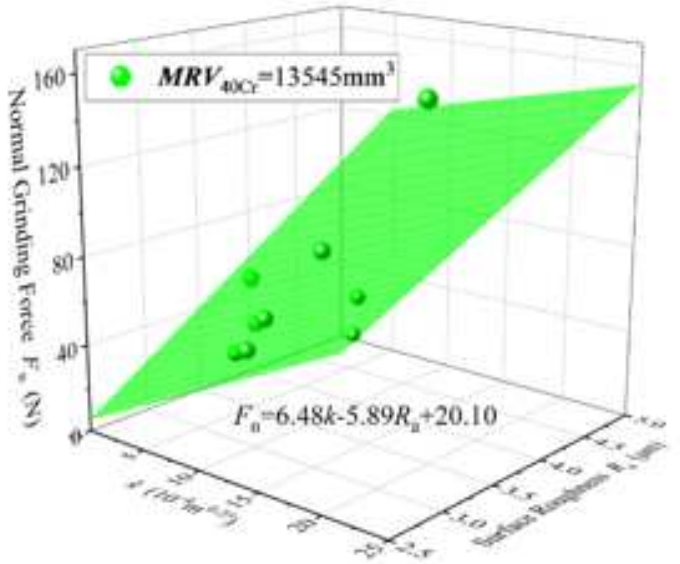

(d)

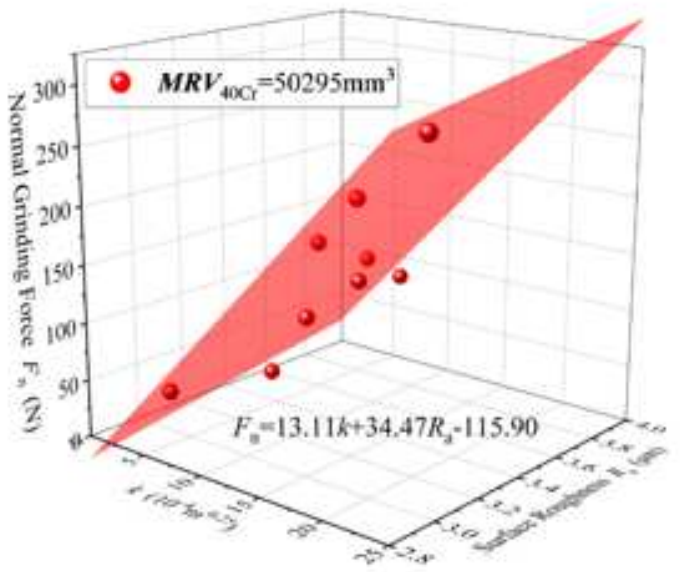

(f)

\section{Figure 6}

The relationship among normal force Fn, parameter $k$, and surface roughness $\mathrm{Ra}$ in different wear stages. Data in (a) all stages, (b) stage 1, (c) stage 2, (d) stage 3, (e) stage 4, (f) stage 5 


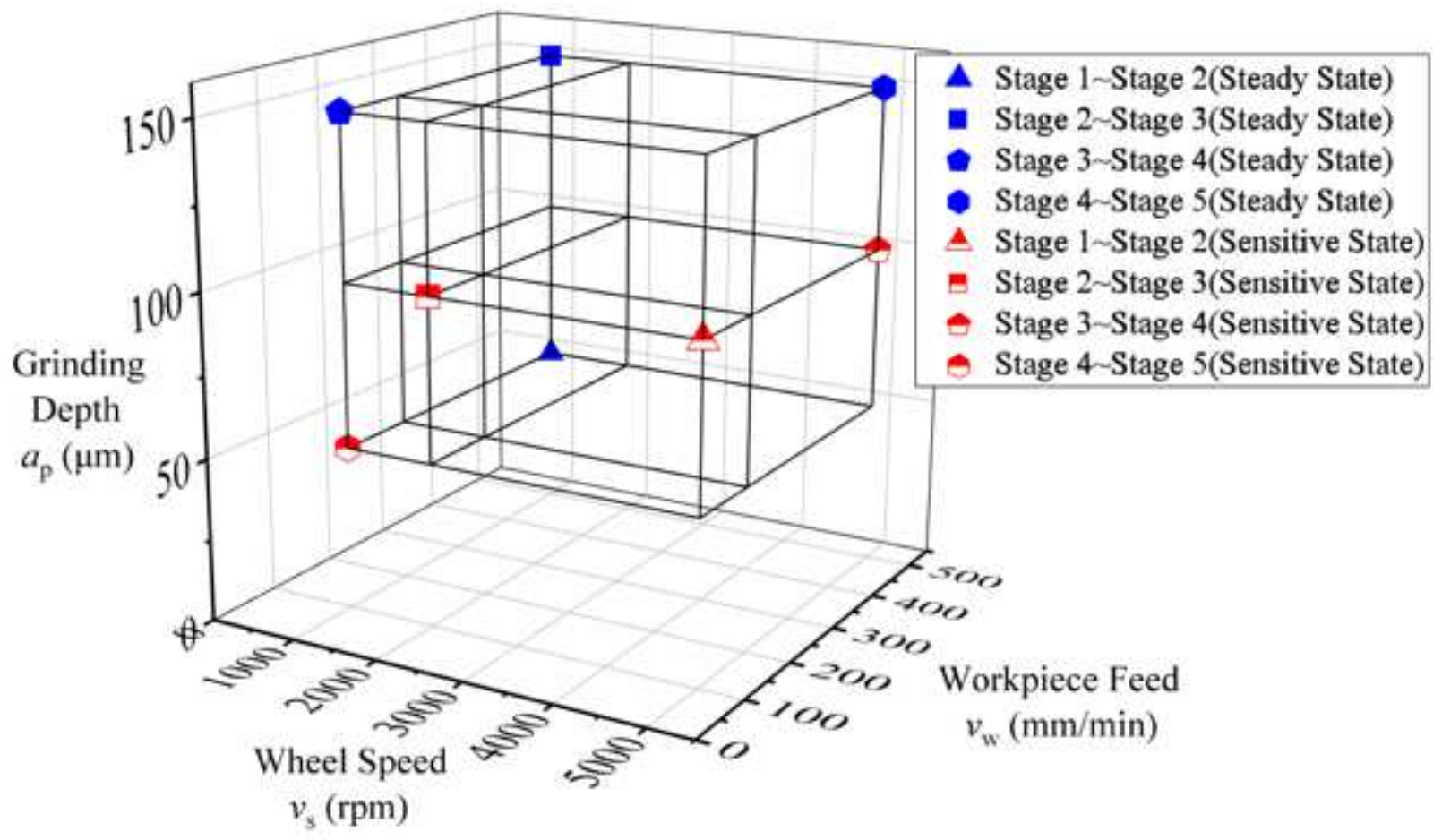

Figure 7

The location of sensitive/steady state of grinding force in different wear stages.

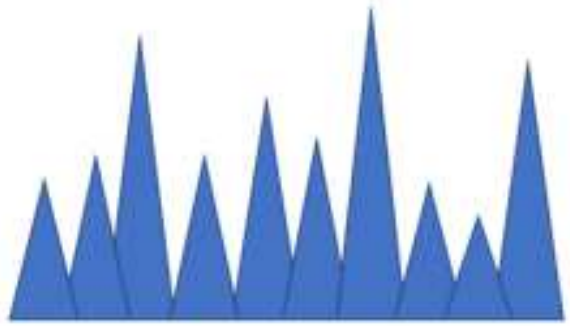

Grits protrusion height of new grinding wheel

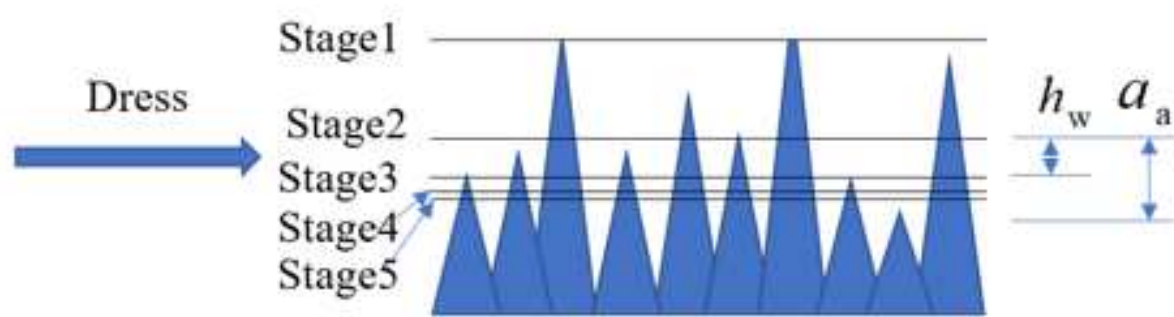

Grits protrusion height of grinding wheel in different wear stage

\section{Figure 8}

The change of abrasive grit protrusion height in different wear stages. 


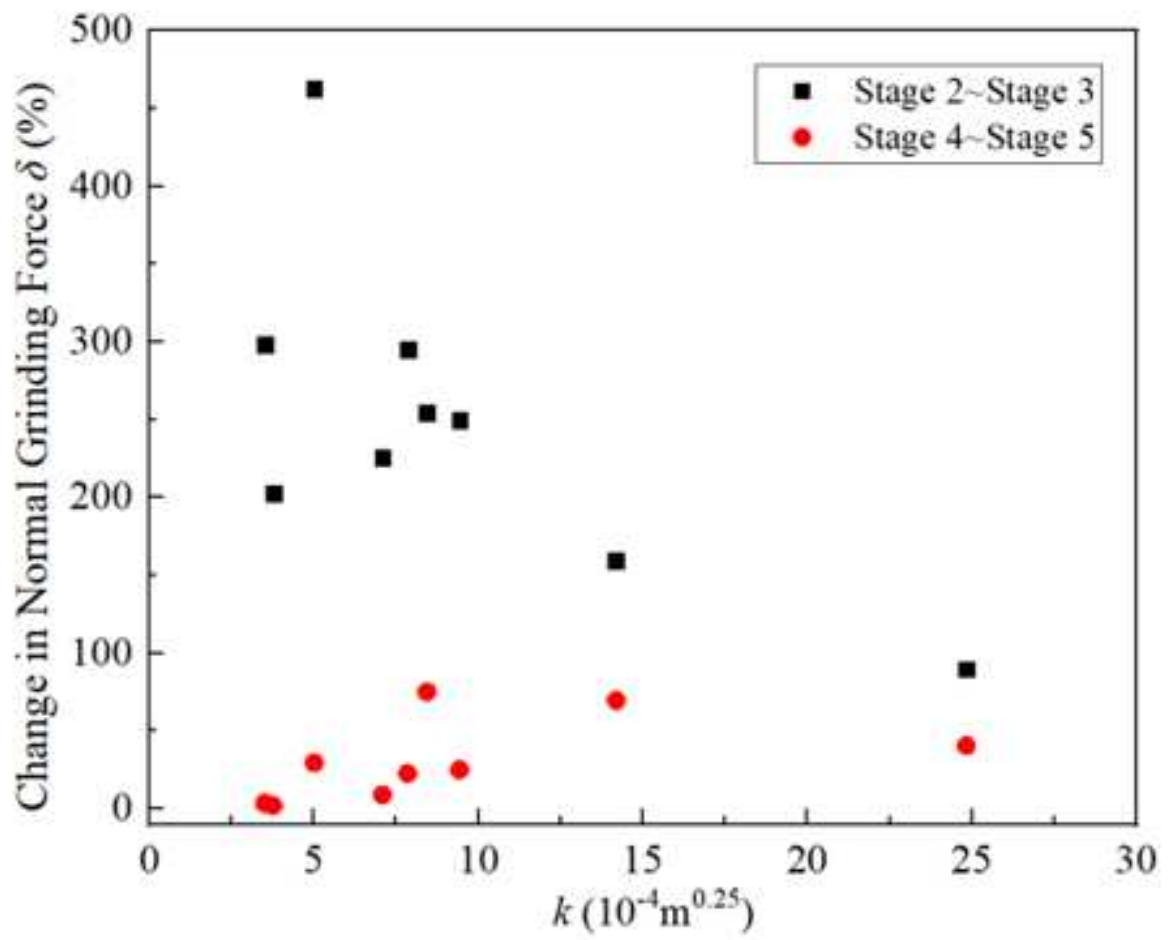

Figure 9

The relationship between the change in normal force $\delta$ and $\mathrm{k}$.

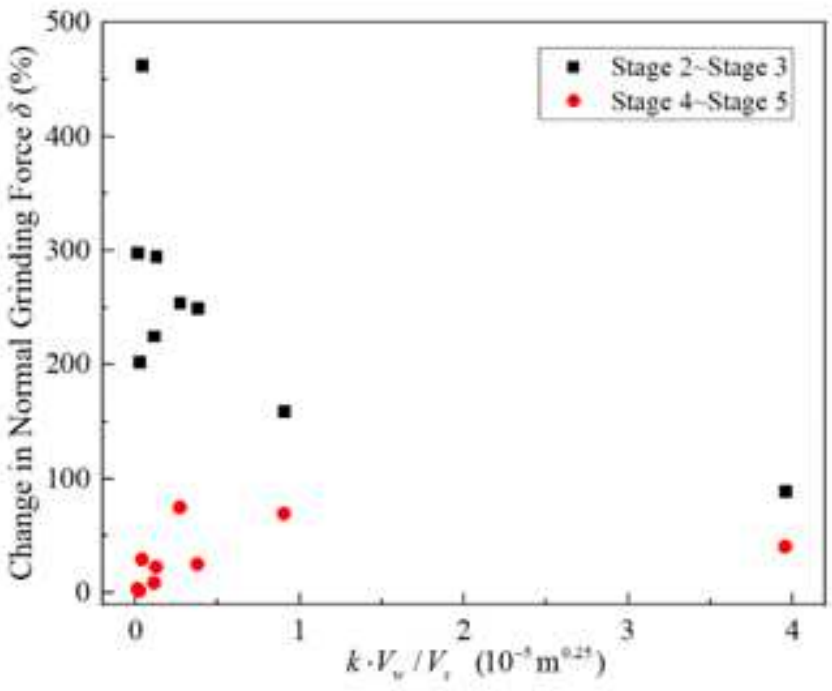

(a)

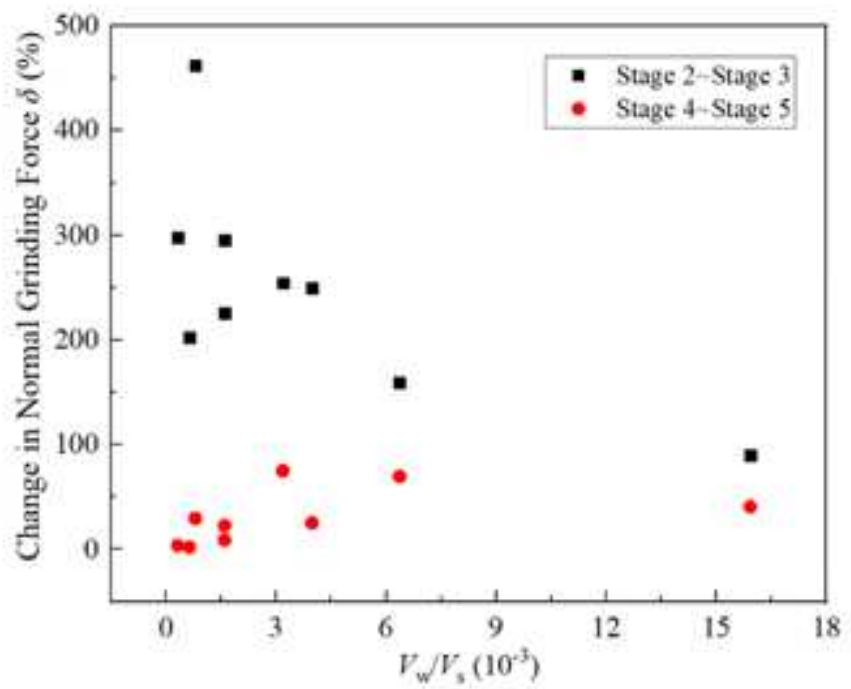

(b)

\section{Figure 10}

The relationship between the change in normal force $\delta$ and (a) kVw/Vs, (b) Vw/Vs. 